NBER WORKING PAPER SERIES

PRICES AND MARKET SHARES IN A MENU COST MODEL

Ariel Burstein

Christian Hellwig

Working Paper 13455

http://www.nber.org/papers/w13455

\author{
NATIONAL BUREAU OF ECONOMIC RESEARCH \\ 1050 Massachusetts Avenue \\ Cambridge, MA 02138 \\ September 2007
}

We thank Andrew Atkeson, Mark Gertler, Mike Golosov, Rebecca Hellerstein, Pete Klenow, John Leahy, Virgiliu Midrigan, and Michael Woodford for helpful discussions, and various audiences at seminars and confererences for their comments. Cesar Serra and Julian Smoller provided outstanding research assistance. The views expressed herein are those of the author(s) and do not necessarily reflect the views of the National Bureau of Economic Research.

(C) 2007 by Ariel Burstein and Christian Hellwig. All rights reserved. Short sections of text, not to exceed two paragraphs, may be quoted without explicit permission provided that full credit, including (c) notice, is given to the source. 
Prices and Market Shares in a Menu Cost Model

Ariel Burstein and Christian Hellwig

NBER Working Paper No. 13455

September 2007

JEL No. E3

\begin{abstract}
$\underline{\text { ABSTRACT }}$
Pricing complementarities play a key role in determining the propagation of monetary disturbances in sticky price models. We propose a procedure to infer the degree of firm-level pricing complementarities in the context of a menu cost model of price adjustment using data on prices and market shares at the level of individual varieties. We then apply this procedure by calibrating our model (in which pricing complementarities are based on decreasing returns to scale at the variety level) using scanner data from a large grocery chain. Our data is consistent with moderately strong levels of firm-level pricing complementarities, but they appear too weak to generate much larger aggregate real effects from nominal shocks than a model without these complementarities.
\end{abstract}

Ariel Burstein

Department of Economics

Bunche Hall 8365

Box 951477

UCLA

Los Angeles, CA 90095-1477

and NBER

arielb@econ.ucla.edu

Christian Hellwig

Department of Economics

UCLA

Box 951477

Los Angeles, CA 90095

chris@econ.ucla.edu 


\title{
Prices and Market Shares in a Menu Cost Model*
}

\author{
Ariel Burstein ${ }^{\dagger} \quad$ Christian Hellwig $^{\ddagger}$ \\ UCLA AND NBER UCLA AND CEPR
}

SePtember 2007

\begin{abstract}
Pricing complementarities play a key role in determining the propagation of monetary disturbances in sticky price models. We propose a procedure to infer the degree of firm-level pricing complementarities in the context of a menu cost model of price adjustment using data on prices and market shares at the level of individual varieties. We then apply this procedure by calibrating our model (in which pricing complementarities are based on decreasing returns to scale at the variety level) using scanner data from a large grocery chain. Our data is consistent with moderately strong levels of firm-level pricing complementarities, but they appear too weak to generate much larger aggregate real effects from nominal shocks than a model without these pricing complementarities.
\end{abstract}

\section{Introduction}

A central question in research on monetary business cycles is whether models based on nominal rigidities can generate persistent delays in price adjustment and large output effects from nominal shocks despite the fact that prices of individual goods change fairly frequently, and both rise and fall by large amounts.

Theories that reconcile the small extent of nominal rigidities at the level of individual goods with slow price adjustment in the aggregate, are typically based on the presence of real rigidities or pricing complementarities, which reduce any individual firm's willingness to respond to a nominal

\footnotetext{
${ }^{*}$ We thank Andrew Atkeson, Mark Gertler, Mike Golosov, Rebecca Hellerstein, Pete Klenow, John Leahy, Virgiliu Midrigan and Michael Woodford for helpful discussions, and various audiences at seminars and conferences for their comments. Cesar Serra and Julian Smoller provided outstanding research assistance.

${ }^{\dagger}$ Email: arielb@econ.ucla.edu

‡Email: chris@econ.ucla.edu
} 
shock if it expects that some other firms don't respond right away (Ball and Romer 1990). Pricing complementarities may result from various features of the firms' microeconomic and macroeconomic environment, such as decreasing returns to scale, firm-specific fixed factors, local or firm-specific input markets, or variable mark-ups at the firm level, or input-output linkages across sectors or real wage rigidities at the aggregate level. From a theoretical perspective, such pricing complementarities can provide any arbitrary amount of amplification and propagation from the micro level to aggregate dynamics. Whether they are indeed large enough to provide enough amplification is therefore largely a quantitative question.

In this paper, we propose a procedure to infer the quantitative significance of certain types of pricing complementarities in the context of a menu cost model of price adjustment, using data on prices and expenditure shares (or market shares) at the level of individual varieties. ${ }^{1}$ Our focus here is on pricing complementarities that result at the firm level, in particular from decreasing returns to scale or the presence of firm-specific inputs that lead to upwards-sloping marginal costs. ${ }^{2}$ The parameters determining firm-level sources of pricing complementarities also determine how a firm's optimal pricing decisions interact with the firm's idiosyncratic shocks. These parameters therefore also have observable implications for prices and market shares of individual goods, so that at least in principle they can be inferred from micro data. Aggregate sources of pricing complementarities, on the contrary, do not directly affect idiosyncratic fluctuations of prices and market shares and can therefore not be inferred from this data.

We then apply this procedure by calibrating our menu cost model to one particular data set on prices and market shares, a scanner data from a large chain of supermarkets in the Chicago area (Dominick's), to assess the quantitative importance of pricing complementarities. Our calibration results suggest that our inferred degree of firm-level pricing complementarities is too weak to generate by itself a strong amplification of nominal shocks at business cycle frequencies.

Our model, described in Section 2, introduces pricing complementarities into an otherwise standard menu cost model (e.g. Golosov and Lucas 2006) by allowing for decreasing returns to scale. We allow for idiosyncratic shocks to both cost and demand in order to match observed fluctuations in prices and market shares at the level of individual varieties.

In section 3, we discuss our inference strategy. Inferring the degree of pricing complementarities

\footnotetext{
${ }^{1}$ Throughout the paper, we focus on market shares, as opposed to physical quantities, as a simple way to isolate fluctuations at the individual variety level from fluctuations at the sectoral level.

${ }^{2}$ We use this formulation for simplicity, and because this form of pricing complementarities is underlying a large number of macroeconomic models with sticky prices (see, for example, Altig, Christiano, Eichenbaum, and Linde 2004, Chari, Kehoe, and McGrattan 2000, and Rotemberg and Woodford 1997).
} 
amounts to jointly inferring the elasticity of demand and the elasticity of the firm's marginal cost (i.e. the returns to scale parameter in our model). Basing this inference on data on comovements in prices and market shares leads to a well-known identification problem. In particular, four basic moments characterizing the data on fluctuations of prices and market shares (frequency and magnitude of price changes, variability of changes in expenditure shares, and the correlation between price and share changes) are not sufficient to calibrate five parameters of our model (elasticity of demand, returns to scale, magnitude of cost and demand shocks, and size of menu costs).

To address this inference problem we add three moments to our calibration: the magnitude of menu costs as a fraction of firm revenues, the average magnitude of price increases relative to price cuts, and the sensitivity of the repricing frequency to the original level of prices.

This choice of additional moment targets is motivated by the following three observations about our model, that we verify numerically. First, increasing the demand elasticity and decreasing the returns to scale makes firm profits more sensitive to mispricing and hence makes firms inclined to change prices more frequently. By targeting a given frequency of price adjustment, we can therefore determine the model parameters using existing measures of the resources that firms spend on price changes as a reference on how large menu costs can be.

Second, firm profits are more sensitive to mispricing when prices are too low rather than too high. This implies that price increases in the model are more frequent than price decreases, but they are also of smaller magnitude. Moreover, this asymmetry becomes larger as we raise the demand elasticity and lower the returns to scale. We can then determine these two parameters by matching separately the frequencies and magnitudes of price increases and decreases.

Finally, firms are more willing to adjust their prices when current market shares are above the median. If cost shocks are the main source of idiosyncratic fluctuations, this occurs when prices are relatively low. If instead demand shocks are relatively more important, this occurs when prices are relatively high. By comparing whether price changes are more or less likely when current prices are high as opposed to low, we can thus infer the relative importance of cost and demand shocks. This is important, because a correct inference of the degree of firm-level pricing complementarities requires that we correctly account for the magnitude of cost and demand shocks.

In Sections 4-7, we apply these insights and calibrate the model to one particular data-set. Ideally one would want to have this data for a comprehensive set of products in the overall economy, but this information is hard to obtain. Instead, we use scanner data from a large chain of supermarkets in the Chicago area. While limited in scope due to its narrow geographic coverage and particular set of grocery products, this dataset has the advantage of providing high frequency information on 
both prices and quantities for many items within narrowly defined product categories.

In Section 4, we report the summary statistics of the data at a monthly frequency to which our model is calibrated. The reported frequencies and magnitudes of price changes are similar to the ones documented by previous studies for a broader set of goods and services (Bils and Klenow, 2005; Klenow and Kryvtsov, 2005; Nakamura and Steinsson, 2007). We complement this with moments on market share fluctuations at the level of individual varieties, and with measures of the asymmetries between price increases and decreases, and the sensitivity of the frequency of price changes to the original level of prices and market shares. For our purposes, the following observations are particularly relevant: (i) the variability of market share fluctuations is fairly large, both when prices are adjusted, and when they are held constant, (ii) fluctuations in prices and market shares are slightly negatively correlated, (iii) well over half of price changes are increases, but they are on average smaller than price decreases, and (iv) prices are significantly more likely to change when market shares are above average, but the frequency of price adjustment is roughly the same for original prices that are above and below average.

In Section 5, we calibrate our model to match these moments in steady state. Based on our data, our inference strategy supports a demand elasticity of roughly 4 and, in its lower range, a returns to scale parameter of 0.55 , implying firm-level pricing complementarities as high as 0.6 so that firms' ideal prices increase by $0.6 \%$ when the aggregate price rises by $1 \%{ }^{3}$ If additionally we assume a strong degree of aggregate pricing complementarities stemming, for example, from real wage rigidities, the overall degree of pricing complementarities is as high as 0.80 . To put these numbers into perspective, Rotemberg and Woodford (1997) calibrate the parameters of a Calvo model to match the impulse response of an estimated VAR, and obtain pricing complementarities of 0.87 , with a similar degree of returns to scale, but a much higher demand elasticity.

In Section 6, we assess the aggregate implications of our inferred level of pricing complementarities. We do so by simulating the impulse response of our model economy to a one-time increase in the growth rate of nominal spending, and computing the resulting cumulative output effects. For the range of parameters consistent with our data, pricing complementarities double the overall output effects, but these effects nevertheless remain an order of magnitude smaller than those obtained with pricing complementarity values based on VAR estimates.

In Section 7, we show that our conclusions are robust along various dimensions, including reasonable changes in calibration targets. Moreover, we explore the role of data on market shares by

\footnotetext{
${ }^{3}$ Our estimates are based on monthly frequency data, and hence cannot be directly compared to other estimates of returns to scale based on lower frequency data, for example Basu and Fernald (1997).
} 
re-calibrating our model to only match observations about prices. Although we can no longer infer all parameters, we still support our main conclusion that firm-level pricing complementarities are at best moderate. Finally, we show that our inferred degree of firm-level pricing complementarities do not change much, if, following Midrigan (2006), we calibrate a modified version of our model that accounts for the occurrence of both small and very large price changes.

In summary, our calibration suggests that firm-level pricing complementarities that generate quantitatively large aggregate amplification effects from nominal rigidities are inconsistent with observations about our micro data. This is largely due to three reasons: First, by increasing the curvature of profits, stronger firm-level pricing complementarities give firms an incentive to change prices much more frequently, so that matching the observed frequency of price changes and the large variability of market shares (even when prices remain constant) requires implausibly large menu costs. Second, a model with stronger pricing complementarities generate much more asymmetry between price increases and decreases than what we observe in the data. Third, with a higher demand elasticity, the observed size of price changes lead to market share fluctuations that are much larger than those observed in the data.

Our analysis relates to several literatures. Golosov and Lucas (2007) calibrate a menu cost model to match empirical facts about price changes at the micro level, and then examine the resulting aggregate implications of a nominal shock. Klenow and Willis (2006) introduce pricing complementarities into this model by allowing for scale-dependent mark-ups. They show that if such pricing complementarities are very strong, matching the price observations at the micro level requires implausibly large cost shocks and very large menu costs. In contrast to these papers, we calibrate our model to match facts on both prices and market shares - which requires augmenting the model with idiosyncratic demand shocks. This is important since, in principle, the inferred degree of pricing complementarities depends on correctly accounting for the relative importance of cost and demand shocks.

Menu cost models with pricing complementarities at the sector or aggregate level also include the work by Gertler and Leahy (2005) and Nakamura and Steinsson (2006). Gertler and Leahy provide a theoretical foundation for a New Keynesian Phillips Curve based on a model with pricing complementarities arising from sector-specific input markets. Nakamura and Steinsson calibrate a model with pricing complementarities resulting from input-output linkages across sectors. In contrast to our work, product level data on prices and market shares plays no role in inferring those sectoral or aggregate pricing complementarities.

A large literature considers the plausibility of amplification mechanisms that are based on 
pricing complementarities by calibrating or estimating rich macroeconomic models on aggregate data (e.g., Altig et. al., 2005; Bergin and Feenstra, 2001; Chari, Kehoe and McGrattan, 2000; Dotsey and King, 2006; Eichenbaum and Fisher, 2007; Kimball, 1995, Rotemberg and Woodford, 1997, among many others). We complement these studies by inferring the degree of some sources of pricing complementarities using micro data.

Finally, in this paper we take a very simplified view of the firm's price-setting problem, and abstract from important characteristics of the micro data, such as inventories and stock-outs, price promotions, a richer market structure and demand systems, and interactions between wholesalers and retailers. Our goal in this paper is not to exhaustively explain all features of the micro data, but to provide a methodology (and apply it for one particular model structure and dataset) to assess the quantitative significance of pricing complementarities in a tractable macroeconomic model. ${ }^{4}$

\section{The Model}

We now present a simple menu cost model of the representative sector (or product category) in the aggregate economy. Time is discrete and infinite. The representative sector is composed of a continuum of varieties, indexed by $i \in[0,1]$. Each variety is produced by a single monopolistic firm. These varieties are purchased by a representative household, who values varieties according to a Dixit-Stiglitz consumption aggregator.

Technology and Demand Structure: The demand for variety $i$ is given by

$$
y_{i t}=a_{i t} Y_{t}\left(p_{i t} / P_{t}\right)^{-\theta}
$$

where $Y_{t}$ denotes aggregate output in period $t, P_{t}=\left[\int_{0}^{1} a_{i t} p_{i t}^{1-\theta} d i\right]^{1 /(1-\theta)}$ is the Dixit-Stiglitz price index for aggregate output, $p_{i t}$ denotes the price of variety $i, a_{i t}$ is an idiosyncratic preference shock for variety $i$ in period $t$, and $\theta>1$ is the demand elasticity parameter.

Each variety is produced by a single monopolist firm, using labor $l_{i t}$ as an input, according to

$$
y_{i t}=z_{i t} l_{i t}^{\alpha}
$$

where $z_{i t}$ is an idiosyncratic cost shock for variety $i$ in period $t$ that shapes its productivity. The parameter $\alpha \leq 1$ determines the returns to scale in production, corresponding to the presence of a firm-specific factor that is costly to adjust at short horizons, or, similarly, to a firm-specific input

\footnotetext{
${ }^{4}$ Goldberg and Hellerstein (2006) and Nakamura (2006) consider pricing with nominal rigidities in richer structural IO models that abstract from general equilibrium considerations.
} 
whose market price is increasing in firm scale. Firms' nominal profits in period $t$, exclusive of menu costs, are given by

$$
\pi_{i t}=p_{i t} y_{i t}-W_{t}\left(y_{i t} / z_{i t}\right)^{1 / \alpha}
$$

where $W_{t}$ denotes the aggregate nominal wage in period $t$. The expenditure share (or market share) of variety $i$ in period $t$ is given by $e_{i t}=p_{i t} y_{i t} / P_{t} Y_{t}$.

Idiosyncratic demand and cost shocks each follow an AR1 process,

$$
\begin{aligned}
& \ln a_{i t}=\rho_{a} \ln a_{i t-1}+\varepsilon_{i t}^{a} \\
& \ln z_{i t}=\rho_{z} \ln z_{i t-1}+\varepsilon_{i t}^{z},
\end{aligned}
$$

where $\varepsilon_{i t}^{a} \sim \mathcal{N}\left(0, \sigma_{a}^{2}\right)$ and $\varepsilon_{i t}^{z} \sim \mathcal{N}\left(0, \sigma_{z}^{2}\right)$ are iid across varieties and over time. We let $\Psi\left(s^{\prime} \mid s\right)$ denote the transition probability function associated with the idiosyncratic shocks, where $s=(a, z)$.

Price Adjustment: In each period, firms observe their draw of demand and cost shocks $s_{i t}=\left(a_{i t}, z_{i t}\right)$, and then decide whether to hire $F$ units of labor to change their price or otherwise keep it constant. The firms maximize the expected net present value of nominal profits, discounted at nominal interest rates:

$$
\max _{\left\{p_{i t}\right\}} \mathbb{E}_{0} \sum_{t=0}^{\infty} \prod_{s=0}^{t-1}\left(1+i_{s}\right)^{-1}\left[\pi_{i t}-W_{t} F \mathbb{I}_{p_{i t} \neq p_{i t-1}}\right],
$$

where $\mathbb{I}_{p_{i t} \neq p_{i t-1}}$ is an indicator variable that takes on the value 1 , if $p_{i t} \neq p_{i t-1}$ and 0 otherwise. Here, $i_{s}$ denotes the nominal interest rate between period $s$ and $s+1$, and $\pi_{i t}$ denotes current profits exclusive of menu costs.

Nominal Spending, Wages, and Interest Rates: We summarize the considerations of general equilibrium by a simple quantity equation that determines aggregate nominal spending, a household Euler Equation that determines nominal interest rates, and an equation relating aggregate nominal spending, wages and prices. Aggregate money supply $M_{t}$ is exogenous and grows at a rate $\mu_{t}$. Aggregate nominal spending $Y_{t} P_{t}$ is equal to the aggregate money supply $M_{t}$. Interest rates are determined by $u_{t}^{\prime} / P_{t}=\beta\left(1+i_{t}\right) u_{t+1}^{\prime} / P_{t+1}$, where $\beta \in(0,1)$ is the discount factor, and $u_{t}^{\prime}$ is the household's marginal utility with respect to aggregate consumption (which equals aggregate output in our model). Nominal wages $W_{t}$ are determined as a geometric average of nominal spending and the aggregate price level, $W_{t}=M_{t}^{1-\gamma} P_{t}^{\gamma}$, where $\gamma \in[0,1)$. This reduced form formulation allows us to capture several interesting special cases: If $\gamma=0$, nominal wages move one for one with nominal spending (or equivalently, real wages move one for one with aggregate output). This case is the one considered in Golosov and Lucas (2007), and can be sustained as a general equilibrium 
outcome when preferences are logarithmic in consumption and linear in labor. Alternatively, in the limit as $\gamma$ converges to 1 , nominal wages become less and less responsive to changes in nominal spending, or equivalently, real wages move less and less with aggregate output (see, for example, Blanchard and Gali 2006). The case with $\gamma>0$ also results from a model where firms use the final good as an intermediate input in production (see, for example, Basu 1995 and Nakamura and Steinsson 2006a), or from additional curvature in the utility function (see, for example, Rotemberg and Woodford 1997).

In this section and in our calibration, we focus on steady-state equilibria in which all aggregate nominal variables grow at a constant rate $\mu$. We then assess the impact of a nominal shock by computing the transition path following a one-time increase in $M$. Our computation method is described in the Appendix. Normalizing all nominal variables by the money supply, we define $\hat{P}_{t}=P_{t} / M_{t}, \hat{p}_{i t}=p_{i t} / M_{t}$ and $\hat{W}_{t}=W_{t} / M_{t}$ as the normalized prices and wages. In a steady-state equilibrium, $\hat{P}_{t}=\hat{P}, \hat{W}_{t}=\hat{P}^{\gamma}, Y_{t}=\hat{P}^{-1}$, and $1+i_{t}=(1+\mu) / \beta$ are constant over time.

Optimal Pricing Decisions: Let $V(\hat{p} ; s)$ denote the present value of profits in a nonstochastic steady state for a firm with current normalized price $\hat{p}$ (prior to its price adjustment decision) and idiosyncratic state $s$. This value function is characterized by the following Bellman equation:

$$
V(\hat{p} ; s)=\max \left\{V\left(p^{*}(s) ; s\right)-\hat{W} F, \hat{\pi}(\hat{p} ; s)+\beta \int_{s^{\prime}} V\left(\hat{p} /(1+\mu) ; s^{\prime}\right) d \Psi\left(s^{\prime} \mid s\right)\right\},
$$

where $p^{*}(s)=\arg \max _{\hat{p}} V(\hat{p} ; s)$ is the firm's optimal normalized price, and $\hat{\pi}(\hat{p} ; s)$ denotes the firm's normalized per-period profits. Notice that if the firm does not adjust, its normalized price depreciates by a factor $1+\mu$. After substituting for $\hat{W}$, normalized profits are given by

$$
\hat{\pi}(\hat{p} ; s)=a(\hat{p} / \hat{P})^{1-\theta}-(a / z)^{1 / \alpha} \hat{P}^{\gamma-1 / \alpha}(\hat{p} / \hat{P})^{-\theta / \alpha} .
$$

The firm's optimal decision rule $\tilde{p}(\hat{p} ; s)$ is characterized by two values $\underline{p}(s), \bar{p}(s)$ around the optimal price $p^{*}(s)$, for which $V(\underline{p}(s) ; s)=V(\bar{p}(s) ; s)=V^{*}(s)-\hat{W} F$. The firm finds it optimal to keep its price constant if $\hat{p} \in[\underline{p}(s) ; \bar{p}(s)]$, and to adjust its price to $p^{*}(s)$ otherwise.

A steady-state equilibrium consists of a decision rule $\tilde{p}(\hat{p} ; s)$ that solves the firms' optimization problem, a cross-sectional distribution $\Phi$ over price-state pairs $(\hat{p} ; s)$ that is stationary under the Law of Motion induced by $\tilde{p}(\hat{p} ; s)$, and a normalized aggregate price level $\hat{P}$ which satisfies $\hat{P}^{1-\theta}=$ $\int a[\tilde{p}(\hat{p} ; s)]^{1-\theta} d \Phi(\hat{p} ; s)$.

With positive menu costs, $\tilde{p}(\hat{p} ; s)$ does not have a simple analytical solution, and thus must be numerically solved for. In the remainder of this section, in order to develop some intuition, we focus on optimal pricing for a firm that faces no menu costs. 
Pricing Complementarities: Let $\hat{p}^{f}(s)$ denote the optimal normalized price for a firm whose menu cost is permanently equal to zero. This optimal price solves the first-order condition $\pi_{p}(\hat{p} ; s)=0$, which gives

$$
\log \hat{p}^{f}(s)=\frac{1}{1+\theta / \alpha-\theta} \log \left(\frac{\theta / \alpha}{\theta-1}\right)+k \log \hat{P}-\frac{1}{\alpha+\theta(1-\alpha)}(\log z-(1-\alpha) \log a),
$$

where

$$
k=1-(1-\alpha \gamma) /(\alpha+\theta-\alpha \theta)
$$

The constant in (2) measures the logarithm of the mark-up over marginal cost. The parameter $k$ is the elasticity of the firm's optimal price with respect to the aggregate price level $\hat{P}$, and is thus referred to as the degree of pricing complementarities. Note that $k>0$ reduces the firm's willingness to respond to a nominal shock if it expects that some other firms won't respond right away. In this sense, $k>0$ plays a key role in inducing a slow response of the aggregate price level to a nominal shock.

The aggregate price level $\hat{P}$ affects the firms' marginal cost (and hence the optimal price) through two channels. On the one hand, if marginal cost is upward-sloping $(\alpha<1)$, an increase in $\hat{P}$ lowers the firm's relative price, thus increasing demand and marginal cost. On the other hand, if $\gamma>0$, an increase in $\hat{P}$ raises nominal wages. We refer to the first channel as firm-level pricing complementarities, and the second channel as aggregate pricing complementarities. Our model abstracts from interactions between the aggregate price and the firms' ideal mark-up.

These two channels are captured by the comparative statics of $k$ with respect to the wage adjustment parameter $\gamma$, the returns to scale parameter $\alpha$, and the demand elasticity $\theta$. With constant returns to scale $(\alpha=1), k=\gamma$, i.e. individual firms' pricing decisions interact only because the aggregate level of prices affects wages. In contrast, with $\alpha<1, k$ is increasing in $\theta$ and in $\gamma$. In addition, $k$ is decreasing in $\alpha$, if and only if $1-\gamma>1 / \theta$, i.e. when decreasing returns to scale are relatively more important for overall pricing complementarities than real wage rigidities. ${ }^{5}$ Note that $\partial k / \partial \gamma$ is increasing in $\alpha$, so stronger decreasing returns to scale weaken the effect of aggregate complementarities $\gamma$ on the overall degree of pricing complementarities $k$ (and similarly, aggregate complementarities weaken or overturn the effect of decreasing returns). The effects of aggregate and firm-level pricing complementarities can therefore not be easily disentangled, and evaluating the effects of either channel requires information about the other.

\footnotetext{
${ }^{5}$ If $\gamma$ is sufficiently high, $k$ is increasing in $\alpha$. For example, if $\gamma=1$, prices will increase in response to an increase in nominal spending when $\alpha<1$ but not when $\alpha=1$.
} 
The parameters $\theta$ and $\alpha$ determine not only the degree of pricing complementarities $k$, but also how prices and quantities of individual varieties respond to idiosyncratic demand and cost shocks. Using (1) and (2), a lower $\alpha$ increases (decreases) the impact of demand shocks on prices (quantities), and reduces the impact of cost shocks on both quantities and prices. We can therefore attempt to infer these two parameters using observed variation in variety-level prices and quantities.

On the other hand, the response of prices and quantities to idiosyncratic shocks does not depend on $\gamma$. Therefore, information on prices and quantities of individual varieties does not shed any light on the value of $\gamma$ in a steady-state with constant inflation. The parameter $\gamma$ only affects the dynamics of prices and quantities out of steady-state level. Therefore, the micro data alone doesn't allow us to completely infer $k$. Our inference of $\theta$ and $\alpha$ nevertheless enables us to identify a range estimate for $k$, based on plausible values for $\gamma$, or estimates based on aggregate data. Moreover, knowing $\alpha$ and $\theta$ enables us to accurately assess the effects of aggregate complementarities $\gamma$.

\section{Inferring Pricing Complementarities}

In this section, we discuss how we can infer the key parameters of the menu cost model using moments of the micro data on prices and market shares. The points of our discussion are verified numerically in our calibrations in Section 5 .

While the elasticity $\theta$ and the returns to scale $\alpha$ are the parameters of most immediate interest, the model has eight other parameters that we need to consider: the growth rate of nominal spending $\mu$, the discount rate $\beta$, the wage elasticity parameter $\gamma$, the menu cost $F$, and the parameters $\left(\rho_{a}, \sigma_{a}\right)$ and $\left(\rho_{z}, \sigma_{z}\right)$ that govern the stochastic processes of productivity and demand shocks. Among these eight parameters, $\mu$ is set equal to the steady-state rate of inflation, $\beta$ is chosen to target the steadystate real interest rate, and $\gamma$ remains unidentified, but doesn't affect our steady-state calibration of the other parameters. To simplify our discussion, we also fix $\rho_{a}$ and $\rho_{z}$, and focus on the five remaining parameters $\left(F, \sigma_{a}, \sigma_{z}, \theta, \alpha\right)$.

The micro data on prices and market shares gives us information on $(i)$ the frequency of price adjustment, $(i i)$ the average magnitude of price changes, $(i i i)$ the average variability of month-tomonth changes in market shares, and $(i v)$ the correlation of changes in prices and shares. ${ }^{6}$ With these four moments, we are still unable to identify the five parameters. If we leave aside the fixed cost $F$ and the frequency of price adjustment, this amounts to the well-known problem of

\footnotetext{
${ }^{6}$ Whenever our model with normally distributed shocks matches the average magnitude of price or share changes, it also matches their variability, and vice versa. We thus chose to target only one of these two moments in our calibration.
} 

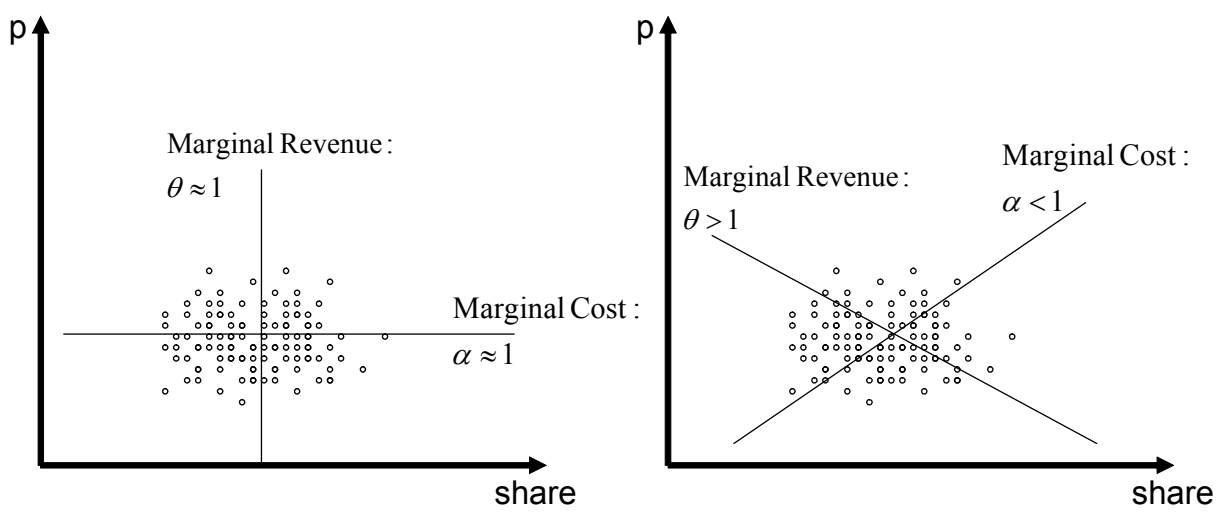

Figure 1: The identification problem

separately identifying the elasticity of demand and marginal cost, and the magnitude of cost and demand shocks, from observed prices and quantities.

In Figure 1, we illustrate this problem by showing how the same data on prices and market shares may be the result of different parameter pairs $(\theta, \alpha)$ - the figure refers to levels, but the same logic applies to fluctuations in prices and market shares. In the left panel, this is done with a demand elasticity close to 1 , and near constant returns, resulting in very weak firm-level pricing complementarities. In the right panel, the same observations are fitted by a more elastic demand schedule, and decreasing returns to scale, and hence stronger firm-level pricing complementarities. More generally, there is a continuum of values of $\theta$ and $\alpha$ that can fit the same data, with each combination resulting in very different degrees of firm-level pricing complementarities.

We thus need to find additional restrictions that will enable us to resolve the problem of inferring $\theta$ and $\alpha$. In the remainder of this section, we discuss three observations about the menu cost model that enable us to do so. ${ }^{7}$

Observation 1: Holding constant the four benchmark moments, the inferred magnitude of menu costs is increasing in the degree of firm-level pricing complementarities (increasing in $\theta$ and decreasing in $\alpha$ ).

\footnotetext{
${ }^{7}$ This approach complements alternative estimation procedures that that try to instrument for variation in cost and demand.

Another alternative would be to directly look for more direct information regarding some parameters. For example, $\theta$ and $\alpha$ also determine the firm's profit rates and mark-ups, and it might therefore seem tempting to calibrate our model to match measures of mark-ups or profits. Such an approach, however, would require us to take an explicit stand on the unmodelled fixed factors of production, how they are compensated, and how they are accounted for in any measure of profit rates.
} 

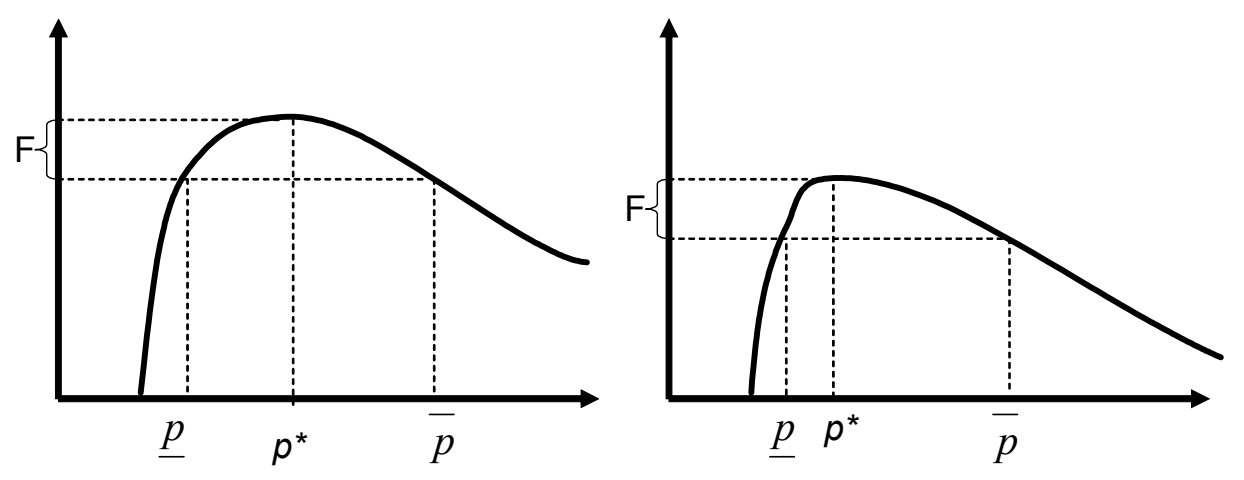

Figure 2: Asymmetry in value function and Ss-bands

In the model, firm profits become more concave in $\hat{p}$, as we lower $\alpha$ and increase $\theta$. Firms thus become more sensitive to mispricing, which tightens the Ss bands and provides an incentive to adjust prices more frequently. Therefore, maintaining the same frequency of price changes requires larger menu costs. We can therefore infer $\alpha$ and $\theta$ by targeting existing empirical measures of the size of menu costs and the other four benchmark moments.

The next observation provides an alternative that enables us to infer $\alpha$ and $\theta$ using additional information on variation in prices and market shares at the level of individual varieties.

Observation 2: Price changes become increasingly asymmetric with stronger firm-level pricing complementarities (higher $\theta$ and lower $\alpha$ ). Price increases become more frequent, but smaller in size relative to price decreases.

In the model, having a price that is too low lowers the mark-up and reduces the profit margin until profits eventually become negative. Having a price that is too high instead reduces the quantity sold, but profit margins are actually even higher than at the optimum. Profits are therefore much less sensitive to price, when price is above the optimum, than when it is below. This asymmetry carries over to the firm's value function, and hence its Ss bands, which are asymmetric around the optimal price $p^{*}$ : the lower Ss band is closer to the optimal price than the upper Ss band. This is illustrated in Figure 2, which plots the firm's value function for a particular realization of $s$, and in Figure 3, which plots the Ss bands (projecting pairs $\left(a, z^{-1}\right)$ into a single dimension on the horizontal axis).

The asymmetry in the Ss bands in turn generates an asymmetry in the frequency and magnitude of price increases and decreases. With no inflation, the firm hits its lower Ss band more frequently than its upper Ss band, implying that it raises its price more often than it lowers it. On the other 


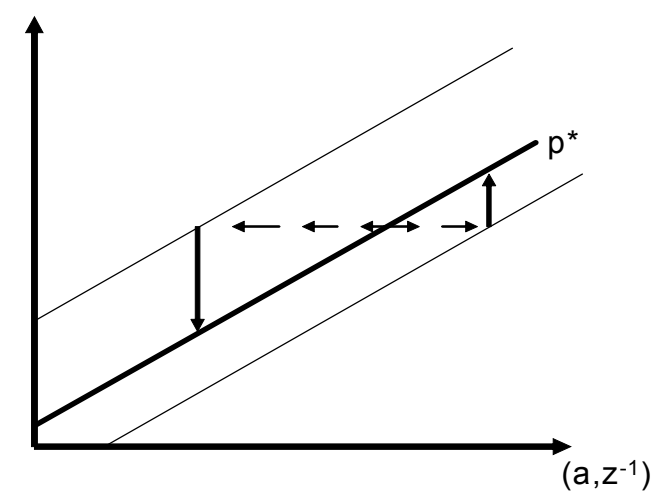

Figure 3: Asymmetry between price increases and decreases

hand, when price increases occur, they tend to be of a smaller magnitude. ${ }^{8}$

Now, how does this asymmetry depend on $\theta$ and $\alpha$ ? The lower is $\alpha$, the more marginal costs respond to quantities, and the higher is $\theta$, the more the firm's mispricing affects its quantity. If prices are too low, the profit margin is then further reduced by the increased quantity (and hence the rise in marginal costs), whereas if prices are too high, the reduction in profits resulting from the lower quantity is mitigated by the fact that marginal costs are also reduced. Therefore, with higher $\theta$ and lower $\alpha$, the asymmetries in the profit function and the Ss bands become even more pronounced, which implies that the asymmetry between price increases and decreases also grows (price increases become relatively more frequent but smaller in size than price decreases).

We can therefore infer $\theta$ and $\alpha$ by calibrating our model to match these asymmetries between price increases and decreases. Trend inflation affects the magnitude of these asymmetries, in particular the fraction of price changes that are increases, but not the fact that they become more pronounced as $k$ increases ( $\theta$ increases, $\alpha$ decreases).

Related to the problem of inferring pricing complementarities is the problem of isolating the relative importance of cost and demand shocks. To see this, note that if demand shocks are relatively more important, large fluctuations in prices at the variety level can only be accounted for in the model by strong decreasing returns to scale. In contrast, if cost shocks are relatively more important, these price fluctuations can be accounted for even with constant returns to scale.

Our inference of pricing complementarities would therefore be biased if we just focused on one source of idiosyncratic shocks. Instead, it is important that we consider a model with both cost and

\footnotetext{
${ }^{8}$ See Burstein (2006), Devereux and Siu (2007) and Ellingsen, Friberg and Hassler (2006) for a related discussion of pricing asymmetries in state dependent sticky price models.
} 

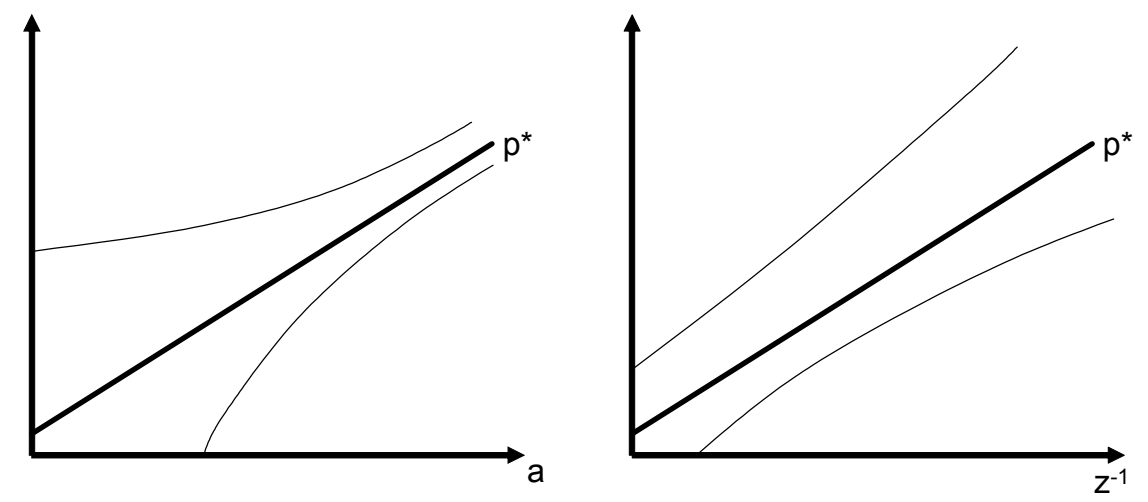

Figure 4: Asymmetry between high and low relative prices

demand shocks, and try to isolate how much of the price and share fluctuations are driven by each. We do this by calibrating the model to all four benchmark moments, in particular the comovement between fluctuations in prices and market shares.

Our third observation provides an alternative for inferring whether price changes are mainly driven by cost or demand shocks, without directly relying on the data on market shares.

Observation 3: Price changes are more likely to occur in periods with large sales (market shares). If cost shocks are relatively more important, this occurs when the original price is low. If demand shocks are relatively more important, this occurs when the original price is high.

Ceteris paribus, profits are more sensitive to mispricing when a variety is in high demand. This in turn leads to narrower Ss bands and a higher frequency of price changes in comparison to when demand is low. If price changes are driven mostly by cost shocks, a variety is in high demand when its price is low. In contrast, if price changes are driven mostly by demand shocks, a variety that is in high demand also tends to have a high price.

Figure 4 illustrates differences in the width of the Ss bands, depending on whether idiosyncratic shocks are to demand (left panel) or to costs (right panel). If cost shocks are relatively more important, price changes are more frequent when the original price is relatively low. If demand shocks are relatively more important, price changes are more frequent when the original price is relatively high. Therefore, how the likelihood of a price change depends on the original price provides information on the relative importance of cost vs. demand shocks.

This argument is based on the premise that price changes are indeed more likely when demand is high. Therefore, we will also need to look at how the likelihood of price adjustment depends on the current level of demand (or the current market share). 
In summary, the first two observations allow us to infer $\theta$ and $\alpha$, and therefore measure the strength of pricing complementarities. All else equal, stronger pricing complementarities require higher menu costs and generate more asymmetries between price increases and decreases. To correctly infer these parameters, we also need to infer the relative importance of cost and demand shocks. These can inferred either from the benchmark moments (in particular the correlation between fluctuations in prices and market shares), or using our third observation, from the sensitivity of the repricing frequency to the level of the initial price.

\section{Data on Prices and Market Shares}

We now apply the ideas described above, designed to guide inference of the model's parameters, using a specific dataset. This dataset measures retail sales by Dominick's Finer Food, a large supermarket chain with 86 stores in the Chicago area, and was prepared by the University of Chicago's Graduate School of Business in cooperation with Dominick's. The product categories included in this dataset include non-perishable food products (e.g. crackers), household supplies (e.g. detergents), and hygienic products (e.g.: shampoo). While limited in scope due to its narrow geographic coverage and particular set of grocery products, this dataset has the advantage of providing high frequency information on both prices and quantities for many items within narrowly defined product categories.

It is a weekly store-level scanner data by universal product code (UPC), ranging between 1989 and 1997. For each UPC it includes weekly sales and retail prices. The dataset includes 29 product categories (e.g.: beer, bottled juice, toothpaste, dish detergent) and more than 4500 UPCs (e.g.: Crest mint 8.2 oz., Tropicana mango $46 \mathrm{oz}$ ). In mapping our model to the supermarket data, each variety corresponds to an individual UPC within a product category. We conduct our analysis of pricing at the chain level. Dominick's follows a chain-wide pricing strategy, with some discretion given to individual stores which results in prices not perfectly correlated across locations. Stores are divided into high, medium, and low pricing zones, depending on the extent of local competition. We only consider stores included in the middle-level pricing zone, which contains the largest number of stores. We focus on market shares, as opposed to physical quantities, to isolate idiosyncratic fluctuations from fluctuations at the level of the product category. In our baseline calculations in the data and the model, a time period corresponds to a four week interval.

In the Appendix, we describe in detail how we construct summary statistics from this data. We construct market shares as the ratio of sales of individual UPCs to total sales across all UPCs 
within its product category in each week. Similarly, we construct relative prices as the ratio of the nominal price of individual UPCs to the aggregate price of its product category (product category prices are constructed as share weighted averages). For each UPC we construct simple averages of market shares and relative prices across stores and weeks within 4 -week periods. For our statistics on chain-wide prices, we measure the median price set by Dominick's across stores for each UPC in a given 4-week period - since price changes are almost, but not perfectly, correlated across stores, using chain-wide average prices would deliver artificially high price flexibility. We compute each moment A-H described below for each UPC, and then compute a weighted average across all UPC's within each product category (using as weights the fraction of sales of each UPCs in total sales of its product category during the total time span). We report each moment for the median product category.

We separately report statistics either including or excluding temporary mark-downs. For our benchmark calibration, we focus on the statistics that exclude temporary mark-downs. In Section 7, we discuss how our results change if we instead use the statistics that include them.

A. Frequency of Price Adjustment: The frequency of price adjustment for each UPC is defined as the fraction of observations with price changes, and the price duration is defined as the inverse of the frequency. Table 1, Row 1, shows that, for the median product category, the price of the average UPC changes every roughly 4 four-week periods (this is equal to $1 / 0.25$ ) excluding temporary price markdowns, and 2.5 four-week periods including temporary price markdowns. In the model calibration, we target a slightly higher average duration of 4.5 periods, in order to make the results comparable to Golosov and Lucas (2007) and Midrigan (2006).

B. Magnitude of Price Changes: We focus on measures of the size of changes in prices over time (and changes over time in the logarithm of market shares in the following subsections), and we do not focus on differences in price levels (or levels of market shares) across varieties at a point in time, because our model abstracts from permanent differences across varieties in quality, size, characteristics, etc., that explain some of the price (and market share) differences across UPCs observed in the data.

Table 1, Rows 2-4, reports three measures to document large changes in UPC prices. Row 2 displays the average magnitude of non-zero price changes. It is roughly $10 \%$ if we exclude temporary price markdowns, and $13 \%$ otherwise. Row 3 displays the standard deviation of non-zero price changes, roughly $15 \%$ excluding temporary price discounts and $19 \%$ if we include them. Row 4 displays the standard deviation of relative prices $p$ (the nominal price of the UPC divided by the nominal price of the product category). Note that here we do not exclude zero price level changes, 
as even in those cases the relative price might change if the aggregate product level price changes. The standard deviation of relative price changes is $7 \%$ if we exclude temporary price markups and $9 \%$ if we include them.

The magnitude of price changes (as well as the magnitude of price increases relative to price decreases described in F) that we observe in the Dominick's supermarket dataset is very similar to that reported in Klenow and Kryvtsov (2005) and Nakamura and Steinsson (2006) for the overall CPI in the US, and in Dhyne et. al. (2006) for the overall CPI in the Euro Area.

In our calibration, we target a 4 -week average magnitude of nominal prices changes equal to $10 \%$.

C. Magnitude of Share Changes: Table 1, Rows 5-7 reports the magnitudes and standard deviations of changes in log-market shares - note that this is different from the standard deviation of the percentage point changes in market shares. The average magnitude of the changes in $\log$ market shares is $17 \%$, and the standard deviation is roughly $25 \%$. The volatility of market shares is only slightly lower if the standard deviation is computed across periods in which the price level remains constant (Row 7 reports a standard deviation of $22 \%$ in this case). If we include temporary price markdowns, log market shares are roughly $5 \%$ more volatile.

In the benchmark calibration of our model, we target a 4-week standard deviation of changes in market shares equal to $25 \%$.

D. Comovement of Prices and Share Changes: Table 1, Rows 8-11 report four statistics that summarize the comovement between changes in prices and changes in market shares. Recall that a model with only idiosyncratic cost shocks would imply a strongly negative correlation between price and market share changes, and a model with only idiosyncratic demand shocks would imply a strongly positive correlation (if $\alpha<1$ ).

Row 8 displays the fraction of price changes in which price and market shares change in the same direction (both either rise or fall). Note that the model with only idiosyncratic cost shocks would imply that all price changes are accompanied with share changes in the opposite signs (provided that prices are set along the elastic part of the demand schedule). For the median product category, this ratio is roughly $45 \%$ if we exclude temporary price markdowns, and $40 \%$ if we include them.

Row 9 and 10 display the correlation between changes in price levels and market share changes (row 10 conditions on observations with non-zero price changes). The correlation is roughly -0.1 if we exclude temporary price markdowns, and -0.2 if we include them.

Row 12 displays the correlation between changes in relative prices and market shares (including zero price change observations). This correlation, which is computed aggregating the price and 
market share data across all stores, is roughly -0.2 if we exclude temporary price markdowns, and -0.35 if we include them. These correlations are only slightly closer to zero if we condition on nominal price adjustment. ${ }^{9}$

The fact that correlations between prices and market shares are far from -1 , and that prices and market shares frequently move in the same direction, suggest that our model requires idiosyncratic demand shocks to account for the observed comovement in prices and market shares. In our benchmark calibration, we target a correlation of price and share changes, conditional on nominal price adjustment, of $-0.20 .^{10}$

E. Menu Costs: Our dataset does not contain information on the costs of changing prices, either by Dominik's or its suppliers. Levy et al. (1999) and Zbaracki et al. (2004) report that firms devote between $0.4 \%$ and $0.7 \%$ of their revenues on average to price changes. Although these numbers are based on a small number of firms and on time-use survey data, they are consistent with the common sense notion that costs of price changes are very small compared to the overall costs and revenues of a firm's activities. In our benchmark calibration, we target average spending on menu costs that are not much larger than $1 \%$ of steady-state revenues.

F. Price Increases vs. Decreases: Rows 13-14 reports the likelihood and size of price increases relative to price decreases. Row 13 shows that for the median product category, roughly $60 \%$ of prices changes are price increases if we exclude temporary price markdowns, and $54 \%$ if we include them, Row 14 shows that the size of price increases is smaller than the size of price decreases (the ratio of the average magnitude of price increases relative to price decreases is roughly 0.85 if we exclude markdowns and 0.90 if we include them).

In pure accounting terms, the steady state inflation rate can be decomposed into the frequencies and magnitudes of price increases and decreases. With the right steady state inflation rate, matching one of these two moments automatically implies that we also match the other one. In our model,

\footnotetext{
${ }^{9}$ We also computed an alternative relative price (market share) measure, defined as the ratio of the current price (market share) of a UPC to the average price (market share) across periods for that UPC. The standard deviation and correlation of these alternative measure of relative prices and market shares are very similar to those reported in Table 1.

We also computed our statistics using physical quantities for each UPC, instead of using market shares. We find that quantities are slightly more volatile than market shares, and the correlation between prices and quantities is slightly more negative than the correlation between prices and market shares.

${ }^{10}$ Note that increases in relative prices driven by temporary price markdowns of a firm's competitor, if associated to a rise in the quantity sold, would generate a negative comovement between relative prices and market shares. Hence, accounting for the observed comovement between relative prices and market shares, which is far from -1 , requires additional sources of demand fluctuation.
} 
the steady state inflation rate primarily impacts the fraction of price increases versus decreases, with only minimal effects on the relative magnitudes. ${ }^{11}$ In order for our results to be robust to small variations in the steady state rate of inflation, we target the relative size of price increases and decreases, rather than the relative frequencies.

G. High vs. Low Prices: Row 15 reports the frequency of price changes conditioning on whether the price level is higher or lower than the median price for each individual UPC. We first compute the median price for each UPC. We then compute the frequency of price change separately for periods in which prices are higher or lower than the median price. We then average each frequency across UPC's, and take the ratio of the high-price frequency to the low-price frequency. We report the median ratio across product categories.

Row 15 shows that, excluding price promotions, the frequency of prices changes is roughly independent on whether pre-change prices are low or high - the ratio of frequencies conditional on prices being high versus low is roughly 0.95. If we include price promotions, prices are then slightly less likely to change if the initial price levels is high.

H. High vs. Low Market Shares: Row 16 redoes the calculations in G, now conditioning on high versus low initial market shares (instead of conditioning on high versus low price levels). We follow the same steps as before, computing the median market share for each UPC, and separately computing the frequency of price changes for periods in which the market share of a UPC is above or below the median. The results in Row 16 suggest that prices are more likely to change in periods when the market share is high (the ratio of frequencies is roughly 1.2).

Table 2 reports the statistics when we depart from the baseline calculations reported in Table 1 along five different dimensions: (1) construct one-week time-periods ( $T=1)$ instead of four-week time periods $(T=4),(2)$ compute weighted averages of relative prices and market shares, instead of simple averages across stores and weeks, (3) exclude UPCs/time periods with average market shares lower than $1 \%$ (instead of $0.1 \%$ in the benchmark case), (4) use data for only one store per product category (the one with the lowest number of missing observations for each product category) instead of computing averages or medians across all middle-level pricing zone, and (5) construct the statistics on price and market share changes using all individual store observations (instead of computing a single chain-wide price and market share for each UPC). Overall, in terms of the basic summary statistics of the data, these perturbations from the baseline computations generate

\footnotetext{
${ }^{11}$ Gagnon (2006) reports, using CPI data for Mexico, that changes in inflation have a large effect on the relative frequencies of price increases and decreases, but not on the relative magnitudes.
} 
slightly lower frequencies of price adjustment, slightly larger price changes, more volatile market shares, and correlations between prices and market shares that are closer to zero. ${ }^{12}$ Moreover, there are only small changes in the magnitude of the asymmetries (both the size of positive relative to negative price changes, and frequency of price adjustment conditional on high and low relative prices). ${ }^{13}$

In Section 7 we perform sensitivity analysis in our model and argue that changes in the calibration targets in the direction suggested by these robustness checks have only a minor impact on the inferred level of firm-level pricing complementarities. Moreover, the choice of targets (especially the relatively small size of price and market share fluctuations) biases our inference toward finding higher levels of firm-level pricing complementarities.

\section{Calibration Results: Steady-State}

In this section, we report our steady-state calibration results. As in the data, we consider a period to be 4 weeks. We set $\beta=0.995$ to target an annual real interest rate of $6 \%$, and $\mu=0.0017$ to match an annual inflation rate of $2.2 \%$, which is the price inflation that we measure in the Dominick's data for the median product category. Finally, we set the persistence parameters $\rho_{z}=\rho_{a}=1 / 2$. In Section 7, we present some sensitivity analysis regarding the persistence parameters.

To determine the remaining five parameters $\left(\theta, \alpha ; F, \sigma_{a}^{2}, \sigma_{z}^{2}\right)$, we fix $\alpha$ at various levels between 0 and 1 , and calibrate the other four parameters to match our four benchmark moments. We then compare how well these different calibrations match our secondary targets to determine what values of $\alpha$ and $\theta$ are more plausible. To provide some intuition about our calibration targets, we first present results when only cost or demand shocks are present $\left(\sigma_{a}=0\right.$ or $\left.\sigma_{z}=0\right)$, and then consider the case when both shocks are active.

Single Shock Model: In Table 3, Columns 1-5, we report results for the model with cost shocks only. In the absence of demand shocks, the correlation between prices and market shares

\footnotetext{
${ }^{12}$ To focus only on the largest UPCs, we also computed (but do not report in our tables) our summary statistics considering within each period the the ten highest market share UPCs in each product category. This procedure implies slightly larger average price changes, slightly less volatile market shares, and a correlation between relative price and market share changes that is closer to 0 .

${ }^{13}$ In related work, Dossche, Heylen and Dirk Van den Poel (2006) infer a relatively small degree of demand-based pricing complementarities using a large scanner dataset of a European retailer. Their data, which covers a wide variety of products such as clothing, equipment, and leisure goods, reveals a very high volatility of quantity changes, as well as comovements between relative prices and quantitites that are significantly larger than -1 .
} 
is -1 , as prices and quantities move along a fixed demand schedule (Row 10). For different values of $\alpha$, we then calibrate the other parameters to match the remaining three benchmark moments (Rows 7-9). $F$ and $\sigma_{z}$ are adjusted to jointly match the frequency and magnitude of price changes. The demand elasticity is then adjusted to match the variability of share changes. The case with $\alpha=0.99$ (Column 1) roughly replicates the calibration results of Golosov and Lucas (2007), with near constant returns to scale.

Table 3, Columns 6-9 report similar results for a model with demand shocks only. With fully flexible prices, such a model would imply that prices and shares are perfectly, positively correlated. With menu costs, the correlation between prices and market shares need not be perfect, but remains large and positive (Row 10). As before, we fix $\alpha$ at different levels, and adjust the remaining parameters to match all the benchmark moments, except for the correlation (Rows 7-9). Note that with only demand shocks, we are no longer able to match the magnitude and frequency of price increases with near constant returns to scale (Column 6). Since prices respond very little to demand shocks in this case, shocks must become very large to match the frequency and magnitudes of price changes. But that in turn would generate implausibly large changes in market shares.

The results in Table 3 illustrate our three observations from the previous section. First, with stronger decreasing returns, both menu costs and idiosyncratic shocks become larger. In the model with cost shocks only and $\alpha=0.35$, the average menu cost represents as much as $5 \%$ of firm revenues (Row 5), and cost shocks become as large as $25 \%$ month-to-month (Row 3). In the demand shock model, this effect is less pronounced, with the magnitude of idiosyncratic demand shocks rising from $24 \%$ to $30 \%$ as $\alpha$ falls from 0.75 to 0.35 (Row 4), and the magnitude of menu costs rising to $0.9 \%$ of revenues (Row 5 ).

Second, lower values of $\alpha$ generate larger asymmetries between price increases and decreases. With cost shocks only, the relative magnitude of price increases to price decreases drops from 0.94 to 0.8 as $\alpha$ drops to 0.35 (Row 11). With demand shocks only, price changes are less asymmetric overall, but the same pattern emerges, with the magnitude of increases relative to decreases dropping from 1.01 to 0.79 as we lower $\alpha$ (Row 11).

Third, the repricing probability depends positively on the level of demand, shaping the frequency of price adjustment conditional on the price level. With cost shocks only, price changes are only roughly $70 \%$ as likely to occur when relative prices are high than when they are low (Row 12), and they are roughly 1.7 times as likely to occur when market shares are high rather than low (Row 13). With demand shocks only, price changes are about 1.2 times as likely to occur when prices are high as opposed to low, and 1.4 times as likely when shares are large as opposed to small. 
The results in Table 3 illustrate the importance of the nature of idiosyncratic shocks in our inference of $\alpha$ and $\theta$, and the resulting degree of pricing complementarities. The model with only demand shocks is easier to reconcile with strong decreasing returns to scale than the model with cost shocks only. In the latter, returns to scale can be at most moderately decreasing $(\alpha \geq 0.75$, $\theta \approx 6$ ), for otherwise they would require implausibly large menu costs. The model with demand shocks, instead, requires stronger decreasing returns $(\alpha \leq 0.55, \theta \approx 3)$ to fit the targets of menu costs and positive/negative price asymmetries. Of course, both of the extremes miss out on the correlation between price and share movements (Row 10) and on the sensitivity of the repricing frequency to the level of prices and demand (Rows 11 and 12), suggesting that both types of shocks are required to match the data.

Model with Demand and Cost Shocks: In Table 4, we report our results for the model with both demand and cost shocks. We fix $\alpha$ at different levels, and then determine the other four parameters to match our four benchmark moments, including the price-share correlation.

For example, beginning with $\alpha=1$, we can match a slightly negative correlation by setting $\theta$ fairly close to 1 : if $\alpha=1$, prices only respond to productivity shocks; $\theta \approx 1$ in turn implies that price and share changes are completely orthogonal to each other. The parameters $F, \sigma_{z}$ and $\sigma_{a}$ are then set to match, respectively, the average duration and average magnitude of price changes, and the variability of share changes. Note that this parametrization implies extremely large mark-ups.

As we lower $\alpha$, the firms' optimal prices respond also to demand shocks, which ceteris paribus makes the correlation between prices and shares less negative. Moreover, firm profits become more sensitive to mispricing, which generates an incentive to have more frequent, but smaller price adjustments. To compensate for this, we need to raise $\theta$ to reduce the correlation between prices and shares, and increase $F, \sigma_{a}$ and $\sigma_{z}$ to maintain the same frequency and magnitude of price and share changes (Rows 2-5).

In contrast to the model with only cost shocks, the shocks no longer appear to be implausibly large given the fluctuations we observe in the data. The $10 \%$ magnitude of cost shocks is similar to the values used in other calibrations. In addition, this value is similar to the magnitudes of changes in wholesale prices in the Dominick's data. ${ }^{14}$ Our measure of the magnitude of demand shocks is still large, which is expected given the fairly large variability in market shares. In the presence of large demand shocks, the model generates a high variability of market shares even

\footnotetext{
${ }^{14}$ The Dominick's data report the cost of acquisition of the current inventory, not the current replacement costs. Whole-sale prices therefore provide a reliable proxy for costs only for items that have a fast turn-over rate, such as certain refrigerated food items.
} 
when prices remain constant. In particular, and consistent with our data, the standard deviation of market shares remains roughly equal to $25 \%$ when it is evaluated only across periods in which prices remain constant.

How well do the different calibrations do in terms of matching our secondary targets? Row 5 shows that a model with $\alpha$ in the range of 0.55 to 0.75 and $\theta$ in the range of 3.8 to 4.4 requires menu costs that are roughly in line with existing empirical measures; lower values of $\alpha$ lead to extremely large menu costs (up to almost $4 \%$ of revenue for $\alpha=0.25$ ).

The same range of $\alpha$ also reasonably accounts for the observed asymmetry between price increases and price decreases: for $\alpha=0.55$, the ratio of the magnitude of price increases relative to decreases is 0.86 (Row 11). Lower values of $\alpha$ lead to asymmetries between increases and decreases that are too large, while higher values of $\alpha$ generate asymmetries that are too small.

Finally, throughout all calibrations, the adjustment probability when market shares are high is roughly $20 \%$ larger than the probability of adjustment when market shares are low (Row 13), and when prices are high, they are roughly $5 \%$ less likely to change than when they are low (Row 12). Both of these values are close to the target, which confirms that our parameterization successfully matches the relative importance of cost and demand shocks. However, since these asymmetries are roughly constant throughout all columns, they do not contribute much to the inferred degree of pricing complementarities.

Implied Pricing Complementarities: The degree of pricing complementarities that is implied by these values of $\alpha$ and $\theta$ depends on the assumed value of aggregate pricing complementarities $\gamma$. With $\gamma=0$, our range estimate of $\alpha \in[0.55,0.75]$ and $\theta \in[3.8,4.4]$ leads to moderate pricing complementarities $k$ between 0.4 and 0.6 . If we allow for strong aggregate pricing complementarities by raising $\gamma$ to 0.85 , our inferred level of $k$ is 0.79 .

How do these parameter values compare with estimates of pricing complementarities that are based on aggregate data? Existing aggregate estimates are obtained by selecting parameters to match the theoretical impulse response function of a Calvo model to the impulse response of an identified VAR in output and inflation, thus requiring the theoretical model to match the inferred persistence of nominal shocks almost by construction. Moreover, this approach does not separately identify the frequency of adjustment from the degree of pricing complementarities, and thus requires an assumption about the former to make some inference about the latter. Rotemberg and Woodford (1997) for example, assume an average price duration of three quarters, and in their model obtain aggregate parameter estimates of $\gamma=0.84$ and $k=0.87$. The underlying structural parameters $\alpha$ 
and $\theta$ are then calibrated to $\alpha=0.68$ and $\theta=7.9$ to match labor market observations. ${ }^{15}$

Our inferred range of pricing complementarities is thus lower than those from aggregate estimates, even if we allow for aggregate pricing complementarities. Relative to macro-based estimates, our inferred returns to scale parameter is quite similar, but our inferred demand elasticity of roughly 4 is substantially smaller, and is more in line with existing estimates from the Industrial Organization literature, including for example, the results in Chevalier, Kashyap and Rossi (2003) that made use of the same data. In the next section, we will explore the quantitative significance of this difference by examining the response of output to a change in money supply in our model. Given that aggregate estimates are based on matching the inferred persistence of nominal shocks, this appears to be the most direct way to compare our micro-based estimate with existing aggregate numbers.

Why don't the data support stronger firm-level pricing complementarities? First, with more strongly decreasing returns and a higher demand elasticity, firms become more sensitive to mispricing and want to change prices more frequently. Matching the observed duration and magnitude of price changes, as well as the large variability of market share fluctuations, even when prices remain constant (these fluctuations in market shares lead to large changes in marginal costs under strong decreasing returns to scale), requires menu costs that are much higher than existing estimates. Second, matching our benchmark moments, a model with stronger pricing complementarities generates much more asymmetry between price increases and decreases than what we observe in the data. Third, a higher demand elasticity would be inconsistent with the magnitude of observed price and share fluctuations. At higher values of $\theta$, the observed price fluctuations of $10 \%$ on average would generate fluctuation in market shares that are much larger than what the data suggest.

\section{Aggregate Impulse Responses}

We now use our inferred parameters to assess the effects of a one-time increase in the growth of nominal spending. Since our focus is on comparing the aggregate response of the model under alternative parameterizations, we only consider a simple change in the path of the money supply (and abstract, for example, from feedback effects from output to monetary policy). Starting from the steady-state distribution of normalized prices, we compute the transition path for prices and output in response to an unexpected one-time $0.5 \%$ increase in $M$, followed by a return to the

\footnotetext{
${ }^{15}$ Notice that these numbers are based on a price duration that is twice as long as the one we found in our data. Assuming a price duration of 4.5 months, the aggregate estimates would imply a much higher value of $k \approx 0.97$.
} 


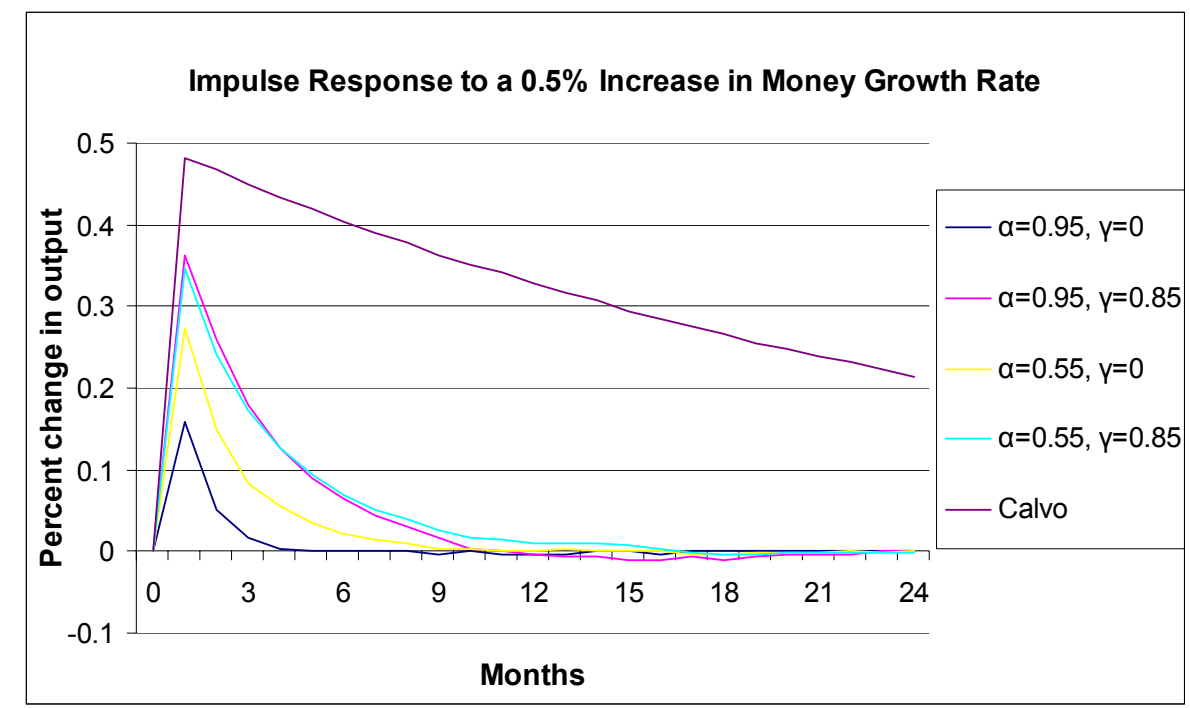

Figure 5: Impulse response of output to a $0.5 \%$ monetary shock

steady-state growth rate $\mu$. Figure 5 and Table 5 report the results from this aggregate experiment.

We consider two values of $\alpha$ : roughly constant returns to scale $(\alpha=0.95)$ and our 'preferred calibration' with the highest level of firm-level pricing complementarities that can be supported by our data $(\alpha=0.55, \theta=4.4)$. The other parameters are set according to the calibrations in Table 4. To explore the role of aggregate pricing complementarities we consider $\gamma=0$ and $\gamma=0.85$ (recall that $\gamma$ cannot be directly inferred from our calibration procedure). Column 3 in Table 5 displays the resulting level of pricing complementarities $k$.

Figure 5 displays the 24-month impulse response of output to the aggregate shock. Columns 4 and 5 in Table 5 provide two measures to quantify this impulse response. Both measures are normalized by the size of the shock. Column 4 reports the response of aggregate output $Y$ on impact. Below, we derive a simple analytic expression for this measure that can be easily interpreted within the context of our model. Column 5 reports the Cumulative Impulse Response (CIR), which sums over time the impulse response of aggregate output. This measure summarizes the cumulative impact of the nominal spending shock on output at different horizons (in particular, we report the CIR for the first 24 months after the shock), and therefore provides a more complete picture of the real effects from the shock. ${ }^{16}$ For example, if a shock increases output one-for-one on impact

\footnotetext{
${ }^{16}$ Our 24 month truncation is innocuous in the menu cost model, in which shocks are fully absorbed within this period. In the Calvo model, which is used for comparison purposes, shocks are more long-lived, so our CIR is a lower bound of the actual real effects implied by the model. See Nakamura and Steinsson (2006) for a more detailed
} 
$(\Delta \ln Y / \Delta \ln M=1)$ and dies out at a linearly declining rate over a period of 24 months, the CIR would be equal to 12 .

\begin{tabular}{|c|c|c||c|c|}
\hline \multicolumn{5}{|c|}{ Table 5: Response to Nominal Shock } \\
\hline \hline$\alpha$ & $\gamma$ & $k$ & $\frac{\Delta \ln Y}{\Delta \ln M}$ & $C I R$ \\
\hline \hline 0.95 & 0 & 0.06 & 0.32 & 0.41 \\
\hline 0.55 & 0 & 0.60 & 0.54 & 1.23 \\
\hline 0.95 & 0.85 & 0.82 & 0.72 & 2.23 \\
\hline 0.55 & 0.85 & 0.79 & 0.69 & 2.34 \\
\hline
\end{tabular}

Two observations stand out from the figure and table:

Result 1: With no aggregate pricing complementarities $(\gamma=0)$, the inferred degree of pricing complementarities $k$ increases the output effects of a nominal shock, but the overall effect remains small.

With constant returns to scale $(\alpha=0.95)$, over two thirds of the nominal shock is absorbed by prices on impact (and output only increases by $1 / 3$ ), and the shock is fully absorbed into prices after 4 months. Under our preferred calibration $(\alpha=0.55)$ the increase in prices is reduced, but still nearly half the effect is absorbed by prices on impact (and output increases by roughly $1 / 2$ ), and the shock is fully absorbed into prices after 9 months. The CIR increases from 0.4 with constant returns, to 1.2 under our preferred calibration.

To assess the magnitude of these effects, Figure 5 displays the impulse response in a Calvo version of our model using Rotemberg and Woodford's (1997) parameter estimates of $\gamma=0.84$, $\theta=7.9$, and $\alpha=0.68$, together with an exogenous monthly adjustment frequency of 0.22 (matching the frequency target of our data). The output response is significantly larger and more persistent, which can be summarized by a CIR of roughly 16. Thus, even though our preferred calibration triples the CIR relative to the model without pricing complementarities, the overall real effects in the estimated Calvo model are roughly 13 times larger.

Result 2: Adding aggregate pricing complementarities does not lead to much stronger output effects within our inferred range of firm-level pricing complementarities

Under our preferred calibration with $\alpha=0.55$, increasing $\gamma$ from 0 to 0.85 raises $k$ from 0.6 to 0.8. The output response on impact increases from 0.54 under $\gamma=0$ to 0.69 under $\gamma=0.85$, and the CIR increases from 1.2 under $\gamma=0$ to 2.3 under $\gamma=0.85$. Adding aggregate complementarities discussion of this measure. 
that roughly match Rotemberg and Woodford's estimates almost double the dynamic output effects, but the effects in the estimated Calvo model are still roughly 7 times larger.

As we had discussed above, stronger decreasing returns to scale weaken the effect of aggregate complementarities $\gamma$, and vice versa. In particular, increasing $\gamma$ from 0 to 0.85 triples the CIR when $\alpha=0.95$ but doubles the CIR when $\alpha=0.55$; likewise lowering $\alpha$ from 0.95 to 0.55 has much bigger effects when $\gamma=0$, than when $\gamma=0.85$. An accurate quantitative assessment of either channel of complementarities therefore requires taking into account the potential contribution of the other.

Underlying both of these results is the fact that there is a strong extensive margin of price adjustment in the menu cost model that is not present in a Calvo model (the so-called 'selection effect' that is emphasized in Golosov and Lucas, 2007, and Midrigan, 2006). In the Appendix, we show along similar lines as Caballero and Engel (2007) that the response of output on impact can be approximated by

$$
\frac{\Delta \log Y}{\Delta \log M} \approx \frac{1-(f+S)}{1-k(f+S)},
$$

where $f$ denotes the frequency of price adjustment, and $S$ the selection effect. The frequency $f$ captures the intensive margin of price adjustment, or the fact that all the firms that do adjust slightly increase their new target price after the shock has occurred. The selection effect $S$ captures the extensive margin, or the fact that after the shock, some firms that would have kept their price constant now prefer to raise it, and some other firms that would have reduced their price now prefer to keep it constant.

We can compute both $f$ and $S$ from the steady-state distribution $\Phi$. In the menu cost model, $S$ is roughly constant at 0.45 across our various parameterizations. It is equal to 0 in the Calvo model. Therefore, with a monthly frequency of price adjustment $f=0.22$ (so that the average duration is $4.5=1 / 0.22$ months), our menu cost model has similar aggregate implications to a Calvo model in which $67 \%$ of all firms change their prices every period.

To illustrate the importance of this selection effect, we can use our decomposition for some simple counterfactuals, which are summarized in Table 6.

\begin{tabular}{|c||c|c|c|c|}
\hline \multicolumn{5}{|c|}{ Table 6: Counterfactuals } \\
\hline \hline$k$ & 0 & 0.6 & 0.80 & 0.97 \\
\hline \hline$\frac{\Delta Y}{\Delta M}(S=0.45)$ & 0.33 & 0.55 & 0.71 & 0.95 \\
\hline$\frac{\Delta Y}{\Delta M}(S=0)$ & 0.78 & 0.90 & 0.95 & $>0.99$ \\
\hline
\end{tabular}

Without pricing complementarities $(k=0)$, the Calvo model $(S=0)$ predicts an output response on impact of 0.78 , whereas the menu cost model $(S=0.45)$ predicts a response of 0.33 . 
For the moderate firm-level complementarities that we infer from the data $(k=0.6)$, increasing $S$ from 0 to 0.45 reduces the output response on impact from 0.9 to 0.55 . If additionally we introduce aggregate pricing complementarities $\gamma=0.85$ so that $k=0.8$, increasing $S$ from 0 to 0.45 reduces the output response on impact from 0.95 to 0.71 . To obtain an output response of 0.95 on impact with a selection effect of $S=0.45$, one would need extremely strong pricing complementarities $(k=0.97)$.

We conclude from this discussion that a menu cost model can generate substantial output effects only if $(i)$ there is a very large degree of pricing complementarities, and (ii) the selection effect is much smaller than what is suggested by our calibration. Pricing complementarities that are purely driven by firm-level decreasing returns are unable, by themselves, to quantitatively account for large output effects. While allowing for large aggregate complementarities can increase $k$ closer to the Rotemberg-Woodford range, the total output response of nominal shock remains small in the presence of a strong selection effect.

\section{Extensions}

In this section, we discuss the robustness of our inference of firm-level pricing complementarities to plausible departures from our benchmark calibration targets. We also explore the role of the quantity data for our inference, and we consider a modified version of our model that can account for additional observations about prices.

Sensitivity Analysis: We perform simple sensitivity checks, recalibrating our model with different parameters or targets, to explore how sensitive our inferred level of pricing complementarities are to the targets that we picked for our benchmark calibration. Results are reported in Tables 7.

We first vary the annual steady-state inflation rate between 0 and $4 \%$. This mainly affects the fraction of price changes that are increases, with little effects on the other moments. This confirms our earlier argument for focusing on the relative magnitudes as the relevant target.

We then consider the effects of lower and higher targets for the frequency of price changes (Nakamura and Steinsson 2006b, for example, argue for a longer average duration of prices). When we raise the average duration of prices in the model to 8 months, our inference on $k$ remains roughly the same: a longer duration leads to a higher menu cost, conditional on changing the price, but since price changes occur less frequently, the average menu cost remains roughly the same magnitude. A similar logic applies if we lower the average duration of prices to 2 months. Note that, even if changing the frequency of prices adjustment leaves the inferred level of $k$ roughly constant, these 
changes in frequency have a large direct impact on the response of the aggregate price level to a nominal shock.

Next, we vary the calibration targets for the magnitudes of price changes, the variability of share changes, and the correlation between price and share changes. We consider a spectrum of targets that one could possibly support based on changes in the measurement of the data moments, as reported for example in Table 2. The correlation between prices and market shares (we consider a range between -0.4 and 0 ) mainly affects the inferred magnitude of cost and demand shocks, but has little effect on inferred $k$. Increasing the volatility of shares from $25 \%$ to $40 \%$ raises the inferred value of $\theta$ and $\alpha$, but also keeps the inferred $k$ roughly equal. On the other hand, the magnitude of price changes does affect the inferred level of $k$ : Increasing the average magnitude of price changes to $15 \%$ reduces the inferred upper bound of $k$ from 0.6 to 0.5 (under $\gamma=0$ ), and lowering the average magnitude of price changes to $5 \%$ increases the inferred level of $k$ as far as 0.78. Note, however, that such small average price changes are much lower than what is suggested by our data and other comprehensive product-level datasets on prices. Overall, we conclude that it is difficult to support firm-level pricing complementarities that are much higher than $k=0.6$ based on our data and inference procedure.

These results also suggest that if we had targeted the moments of the data that do not exclude temporary price markups (reported in Tables 1 and 2), our inferred firm-level pricing complementarities would be even smaller, since prices and market shares are more volatile if we include sales. By filtering out sales, we thus also err on the side of caution with regards to our conclusion that firm level complementarities appear to be relatively weak.

We also conduct some sensitivity analysis with regards to the persistence parameters $\rho_{a}$ and $\rho_{z}$, reported in Table 8 . We can see that changes in the persistence of idiosyncratic shocks have little effect on our inference of pricing complementarities. Hence, bringing additional information on the autocorrelation of prices and market shares to guide the choice of these persistence parameters would most likely not have a major effect on our results.

The Role of Quantity Data: Next, we explore the role of the data on quantities for our inference strategy and results. This is important, since the pricing facts are much better studied, and have been observed over much broader datasets such as the CPI data, whereas our facts on quantities are based on the Dominick's data.

For this purpose, we recalibrate our benchmark model using price data only. We fix $\alpha \in(0,1)$ at different levels, and calibrate the other parameters to match the frequency and magnitude of price changes (as before), the relative magnitude of increases vs. decreases, and the relative frequency of 
changes conditional on the current price being above or below the mean. We then compare how well the different calibrations match the remaining moments, in order to examine how our conclusions rely on information on market shares. Results are reported in Columns 1-8 of Table 9.

For $\alpha \leq 0.75$, the inferred magnitude of the menu cost is roughly constant at $1 \%$, which is close to our target. This suggests that the information about menu costs is not sufficient to differentiate between these different values of $\alpha$. However, over the same set of calibrations, the inferred degree of firm-level pricing complementarity remains between 0.52 and 0.6 ; with $\gamma=0.85, k$ is bounded above by 0.85 . Hence, while the precise configuration of $\alpha$ and $\theta$ is not identified on the basis of price data only, we can infer an upper bound for $k$ that is very similar to the one we obtained in our benchmark calibration.

The market share moments can then be used as additional targets to separately infer $\theta$ and $\alpha$. Market shares are more volatile, and the effect of share levels on the probability of price changes much larger, when $\alpha$ is closer to 1 . As in the main calibration, a value of $\alpha=0.55$ exactly matches these two moments; higher values of $\alpha$ imply share movements that are too large and generate too much asymmetry between high and low shares, whereas lower values of $\alpha$ generate share movements that are too small and not sufficiently asymmetric.

In summary, our general conclusion about the magnitude of firm-level pricing complementarities does not rely heavily on our market share data; our inference on $\alpha$ and $\theta$, however, does. Separately inferring $\alpha$ and $\theta$ leads to a more precise evaluation of the overall degree of pricing complementarities if $\gamma>0$.

As a further check, we also considered a version of our model in which prices are set before the realization of idiosyncratic demand shocks, and after the realization of cost shocks. Even though this modified model does not account for the observed contemporaneous comovements between prices and market shares, when following the calibration procedure discussed in this section and target the two asymmetries, the inferred level of pricing complementarities is very similar to the one obtained in the benchmark model.

Alternative Shock Distributions and Small Price Changes: As discussed in detail in Midrigan (2006), the distribution of price changes in the Dominick's data has fat tails, and almost $30 \%$ of all price changes are small in magnitude, i.e. less than $50 \%$ of the median absolute price change. Midrigan shows that when accounting for these features, the model produces a smaller selection effect, and hence stronger real output effects from nominal shocks. We now consider the following modification of our model to account for these two additional price facts, and examine whether they affect our inference results on the degree of pricing complementarities. 
To generate small price changes, we embed a simple time-dependent component into the pricing decisions by assuming that in each period, there is a probability $q$ that firms get to change their price for free. We choose $q$ to match the fraction of small price changes. To generate fat tails in price changes, we assume that cost and demand shocks are both AR1 processes whose innovations follow a Beta distribution. Specifically, we assume that cost shocks $z_{i t}$ follow

$$
\ln z_{i t}=\rho_{z} \ln z_{i t-1}+\left\{\begin{array}{l}
+\sigma_{z} \varepsilon_{i t}^{z} \text { with probability } 1 / 2 \\
-\sigma_{z} \varepsilon_{i t}^{z} \text { with probability } 1 / 2
\end{array},\right.
$$

where $\varepsilon_{i t}^{z}$ is drawn from a Beta distribution $\beta(0.05 ; 1.3)$. Idiosyncratic demand shocks follow an analogous random process. The parameters of the Beta distribution are the same as those used by Midrigan (2006). They imply a higher kurtosis of price changes, consistent with the Dominick's data.

The results from the modified model are reported in Columns 9-13 of Table 9. As before, we fix $\alpha$, and calibrate the other four parameters $F, \theta, \sigma_{a}$ and $\sigma_{z}$ to match our four benchmark moments on prices and market shares. Our calibration leads to a slightly higher inferred level of pricing complementarities (the upper bound is 0.65 instead of 0.6), that is accounted for by a lower level of $\alpha$. Hence, the model can match the observed frequency of price changes at low values of $\alpha$, with a slightly lower level of menu costs than in the benchmark model. To understand this result, note that the fat-tailed distribution reduces the role of the returns to scale parameter on the firms' desire to change prices (for example, if idiosyncratic shocks are either zero or large in absolute value, price changes occur only if non-zero shocks occur, for a broad range of parameter values for $\alpha$ and $F$ ). These effects have only a small impact on our inferred level of $k$, even with a high level of kurtosis in the shocks.

The aggregate effects of nominal shocks in the modified model are more persistent: the Cumulative Impulse Response increases from 1.2 in our benchmark model, to 5.3 in the modified model, if $\gamma=0$, and from 2.3 to 9 , if $\gamma=0.85$.

We conclude that accounting for these two additional price facts has only a minimal effect on the inferred degree of pricing complementarities, but the model generates stronger output effects due to a reduction of the extensive margin of price adjustment.

\section{Conclusion}

In sticky price models, pricing complementarities play an important role in determining the real effects of a monetary disturbance. In this paper, we have evaluated the quantitative importance 
of one type of pricing complementarities, based on upwards-sloping marginal costs, in a menu cost model with idiosyncratic cost and demand shocks that is designed to match features of the micro data on prices and quantities at the level of individual products. Given that the parameters determining the response to idiosyncratic shocks also shape the aggregate response to nominal spending shocks, the model's ability to match micro data provides an additional degree of discipline over evaluations that are based solely on aggregate data. Our results suggest that firm-level complementarities that are consistent with the micro data are unable, on their own, to generate large aggregate effects.

That said, there are several important caveats to our approach and results, in addition to the robustness checks and extensions that we have already discussed. First, our calibration abstracts from sector-level or aggregate shocks. Our data, however, suggest that these shocks may be fairly large and induce important fluctuations in sectorial price and spending levels. To the extent that sectoral shocks add to the firms' desire to change prices, we conjecture that they would only reinforce our conclusions, since our calibration would then require larger menu costs and imply weaker pricing complementarities to match the data moments on prices and shares. ${ }^{17}$

Second, we had to rely on price-quantity data from a very small and highly specific set of goods to draw inference on important aggregate questions. This raises the obvious question of how representative our data is of the aggregate economy. While an adequate answer to this question requires similar data sources from other sectors, the calibration that matches only the pricing facts (Table 9) lends some support to our main conclusion rejecting stronger pricing complementarities. To us this is reassuring, since the pricing facts are observed across a much wider set of data (including the BLS data for the consumer price index), and can therefore be expected to be much more representative of the aggregate economy.

Third, we have focused on one specific form of pricing complementarities at the firm level, which is based on increasing marginal costs at the level of individual varieties, and we have abstracted from complementarities resulting from variation in desired mark-ups (such as Kimball, 1995, or more recently, Klenow and Willis, 2006). We believe that some of our insights extend to those types of complementarities, but it remains an open question whether they will significantly change our quantitative results.

Finally, by taking a very simplified view of the firm's price-setting problem, we have abstracted

\footnotetext{
${ }^{17}$ In addition, aggregate fluctuations in prices, costs, or spending, as well as measures of synchronization of price changes, may also be useful for more direct ways of inferring pricing complementarities, which would complement the approach we have explored in this paper (see, for example, Gopinath, Itskhoki, and Rigobon 2007).
} 
from important characteristics of the micro data, such as inventories and stock-outs, price promotions, a richer market structure and demand systems, and interactions between wholesalers and retailers. Future work will have to assess how these channels affect the firms' pricing decisions at the micro level, as well as aggregate dynamics. In this respect, our approach is not designed to capture all these features of the micro data, but to provide a methodology to assess their aggregate implications within the context of a tractable macroeconomic model.

\section{References}

[1] Altig, David, Lawrence Christiano, Martin Eichenbaum, and Jesper Linde (2004), "FirmSpecific Capital, Nominal Rigidities and the Business Cycle," working paper, Northwestern University.

[2] Ball, Laurence, and David Romer (1990), "Real Rigidities and the Non-Neutrality of Money," Review of Economic Studies, 57, 187-204.

[3] Basu, Susanto (1995), "Intermediate Goods and Business Cycles: Implications for Productivity and Welfare," American Economic Review, 85, 512-531.

[4] Basu, Susanto, and John Fernald (1997), "Returns to Scale in U.S. Production: Estimates and Implications," Journal of Political Economy, 105, 249-83.

[5] Bils, Mark, and Pete Klenow (2004), "Some Evidence on the Importance of Sticky Prices," Journal of Political Economy, 112, 947-985.

[6] Blanchard, Olivier, and Jordi Gali (2006), "Real Wage Rigidities and the New Keynesian Model," working paper, CREI and MIT.

[7] Burstein, Ariel (2006), "Inflation and Output Dynamics with State Dependent Pricing Decisions," Journal of Monetary Economics, 53, 1235-1257.

[8] Caballero, Ricardo, and Eduardo Engel (2007), "Price Stickiness in Ss Models: New Interpretations of Old Results," Journal of Monetary Economics, 54S, 100-121.

[9] Caplin, Andrew and Daniel Spulber (1987), "Menu Costs and the Neutrality of Money," Quarterly Journal of Economics, 102, 703-25. 
[10] Chari, V.V., Patrik Kehoe, and Ellen McGrattan (2000), "Sticky Price Models of the Business Cycle: Can the Contract Multiplier solve the Persistence Problem?" Econometrica, 68, 11511179 .

[11] Chevalier, J., A. Kashyap, and P. Rossi (2003), "Why Don't Prices Rise During Periods of Peak Demand? Evidence From Scanner Data," American Economic Review, 93, 15-37.

[12] Christiano, Lawrence, Martin Eichenbaum, and Charles Evans (2005), "Nominal Rigidities and the Dynamic Effects of a Shock to Monetary Policy," Journal of Political Economy, 113, $1-45$.

[13] Devereux, Michael and Henry Siu (2007), "State-dependent Pricing and Business Cycle Asymmetries," International Economic Review, 48, 281-310.

[14] Dhyne, Emmanuel, L. J. Alvarez, H. L. Bihan, G. Veronese, D. Dias, J. Hoffmann, N. Jonker, P. Lunnemann, F. Rumler and J. Vilmunen (2006), "Price Changes in the Euro Area and the United States: Some Facts from Individual Consumer Price Data," Journal of Economic Perspectives, 20 171-192.

[15] Dotsey, Michael and Robert King (2006), "Pricing, Production, and Persistence," Journal European Economic Association, 4, 893-928.

[16] Dossche, Maarten, Freddy Heylen and Dirk Van den Poel (2006), "The Kinked Demand Curve and Price Rigidity: Evidence from Scanner Data," working paper, National Bank of Belgium.

[17] Eichenbaum, Martin, and Jonas Fisher (2007), "Estimating the frequency of price reoptimization in Calvo style models, Journal of Monetary Economics, forthcoming.

[18] Ellingsen, Tore, Richard Friberg and John Hassler (2006), "Explaining Asymmetric Price Adjustment," working paper, Stockholm School of Economics and Stockholm University.

[19] Gagnon, Etienne (2006), "Price Setting during Low and High Inflation: Evidence from Mexico," working paper, Federal Reserve Board.

[20] Gertler, Mark, and John Leahy (2005), "A Phillips Curve with An Ss Foundation," working paper, New York University.

[21] Goldberg, Pinelopi, and Rebecca Hellerstein (2006), "A Framework for Identifying the Sources of Local Currency Price Stability with an Empirical Application," working paper, Yale University and Federal Reserve Bank of New York. 
[22] Golosov, Mike, and Robert Lucas (2007), "Menus Menu Costs and Phillips Curves," Journal of Political Economy, 115, 171-199.

[23] Gopinath, Gita, Oleg Itskhoki and Roberto Rigobon (2007), "Currency Choice and Exchange Rate Pass-through," working paper, Harvard University.

[24] Kimball, Miles (1995), "The Quantitative Analytics of the Basic Neomonetarist Model," Journal of Money, Credit and Banking, 27, 1241-77.

[25] Klenow, Pete, and Olexei Kryvtsov (2005), "State-Dependent or Time-Dependent Pricing: Does It Matter for Recent U.S. Inflation?" working paper, Stanford University and Bank of Canada.

[26] Klenow, Peter and Jonathan Willis (2006), "Real Rigidities and Nominal Price Changes," working paper, Stanford University and Federal Reserve Bank of Kansas City.

[27] Levy, Daniel, Mark Bergen, Shantanu Dutta, and Robert Venable (1999), "Menu Costs, Posted Prices, and Multi-Product Retailers," Journal of Money, Credit, and Banking, 31, 683-703.

[28] Midrigan, Virgiliu (2006), "Menu Costs, Multi-Product Firms and Aggregate Fluctuations," working paper, Ohio State University.

[29] Nakamura, Emi (2006) "Accounting for Incomplete Pass-Through," working paper, Harvard University.

[30] Nakamura, Emi, and Jon Steinsson (2006) "Monetary Non-Neutrality in a Multi-Sector Menu Cost Model," working paper, Harvard University.

[31] Nakamura, Emi, and Jon Steinsson (2007) "Five Facts About Prices: A Reevaluation of Menu Cost Models," working paper, Harvard University.

[32] Rotemberg, Julio, and Michael Woodford (1997), "An Optimization-Based Econometric Framework for the Evaluation of Monetary Policy," 1997 NBER Macroeconomics Annual, 297-346.

[33] Woodford, Michael (2003), Interest and Prices: Foundations of a Theory of Monetary Policy, Princeton, NJ: Princeton University Press. 
[34] Zbaracki, Mark, Daniel Levy, Mark Ritson, Shantanu Dutta, and Mark Bergen (2004), "Managerial and Customer Costs of Price Adjustment: Direct Evidence from Industrial Markets," Review of Economics and Statistics, 86, 514-533.

\section{Appendices}

\section{Construction of descriptive statistics}

We index weeks by $w$, product categories by $i$, UPC's by $j$, and stores by $k$. We construct market shares, $e_{k w}^{i j}$, as the ratio of sales of $\operatorname{UPC}(i, j)$ in store $k$ and week $w$, to total sales across all UPCs within product category $i$ in store $k$ and week $w$. Similarly, we construct relative prices $p_{k w}^{i j}$ as the ratio of the nominal price $P_{k w}^{i j}$ of $\operatorname{UPC}(i, j)$ in store $k$ in week $w$ to the aggregate price $P_{k w}^{i}$ of product category $i$ in store $k$ in week $w$ (product category prices $P_{k w}^{i}$ are averages of individual price levels using store $k$, week $w$ market shares as weights). We also construct an indicator variable $x_{k w}^{i j}$ of temporary price mark-downs, defined as a price reduction that is reversed to its original value in no more than 6 weeks. That is, $x_{k w}^{i j}=1$ if $P_{k w}^{i j}<P_{k w^{\prime}}^{i j}=P_{k w^{\prime \prime}}^{i j}, w^{\prime}<w$, $w^{\prime \prime}>w$, for at least one pair $\left\{w^{\prime}, w^{\prime \prime}\right\}$ such that $w^{\prime \prime}-w^{\prime} \in\{2,3,4,5,6\}$, and $x_{k w}^{i j}=0$ otherwise. $^{18}$

We aggregate the data across weeks and stores as follows. We define time periods as $T$-week intervals, and we index periods by $t$. That is, period $t=1$ includes weeks $w=1, \ldots, T$, period $t=2$ includes weeks $w=T+1, \ldots, 2 T$, and so forth. We aggregate the data on relative prices and market shares by taking simple averages across stores and weeks within a $T$ week time period. For each time period, we then exclude UPC for which we do not observe at least 4 consecutive periods with positive market shares before and after the current period. ${ }^{19}$ The resulting relative prices and shares are denoted by $p_{t}^{i j}$ and $e_{t}^{i j}$ (note that these measures do not have a store subindex $k$ ). We report separately summary statistics that include and exclude temporary price markdowns, where the latter are computed using only observations with $x_{k w}^{i j}=0$. We also report the summary statistics of the data if we use weighted averages instead of simple averages across stores and weeks, if we focus on data for only one store (the one with the lowest number of missing observations), and if we separately consider price and market share changes across all individual stores for each UPC (rather than constructing one chain-level price and market share for each individual UPC).

\footnotetext{
${ }^{18}$ The $\mathrm{V}$ pattern that we use to construct a sales indicator is closely related to the definition of "filter B" in Nakamura and Steinsson (2006b). It is more restrictive than that in Midrigan (2006), who does not impose price reductions to return to their original level when defining a sale.

${ }^{19}$ Our summary statistics are roughly unchanged if we do not filter out UPCs with a minimum number of consecutive periods with positive sales.
} 
For our statistics on changes in chain-wide price levels, we do not calculate an average price across weeks and stores - doing this would deliver artificially high price flexibility as simple price averages would reflect changes in only a subset of (some) individual store/week prices. Instead, we measure the median price set by Dominick's across stores (within the medium pricing zone) for each UPC in a given time period. If we observe more than one price observation per time period when $T>1$, we use the price observation corresponding to the first available week. In the calculations that exclude temporary price mark-downs, we remove price observations with $x_{k w}^{i j}=1$.

Our baseline statistics are constructed using 4 week time periods $(T=4)$ - the time length of a period in the calibration of our model, and abstracting from UPC/periods with market shares that are sufficiently small (i.e. 0.1\%). We discuss how the results change if the moments of the data are constructed in alternative ways.

\section{Approximation of aggregate response to nominal shock}

Here, we derive and briefly discuss the approximation formula for the response of prices on impact that we used in Section 6. We approximate the optimal pricing strategies by $\log p_{t}^{*}(s)=$ $\rho^{*}(s)+\log \hat{p}^{f}\left(s ; \hat{P}_{t}\right), \log \bar{p}_{t}(s) \approx \bar{K}(s)+\log p_{t}^{*}(s)$, and $\log \underline{p}_{t}(s) \approx \underline{K}(s)+\log p_{t}^{*}(s)$, where $\rho^{*}(s)=\log p^{*}(s)-\log \hat{p}^{f}\left(s ; \hat{P}^{S S}\right)$ denotes the steady-state front-loading factor, and $\underline{K}(s)=$ $\log \underline{p}(s)-\log p^{*}(s)$ and $\bar{K}(s)=\log \bar{p}(s)-\log p^{*}(s)$ denote the steady-state Ss-bands, in terms of deviation from the target. When computing the aggregate response of our model to a change in money growth in Section 6, we also follow this approximation.

With this approximation, the ideal flexible price $\log \hat{p}^{f}(s ; \hat{P})$, and the approximated target price $\log p_{t}^{*}(s)$ and Ss-bands $\log \bar{p}_{t}(s)$ and $\log \underline{p}_{t}(s)$ all increase by the same magnitude $\delta$, in the initial period of impact of a shock to nominal spending (relative to the counterfactual with steadystate inflation). As a function of $\delta$, the response of prices on impact (net of steady-state inflation) $\Delta \log P$ is approximated by

$\Delta \log P \approx \int_{s} \int_{\hat{p} \leq \underline{p}_{t}(s)}\left(\log p_{t}^{*}(s)-\log \hat{p}\right) \phi(\hat{p} ; s) d \hat{p} d s+\int_{s} \int_{\hat{p} \geq \bar{p}_{t}(s)}\left(\log p_{t}^{*}(s)-\log \hat{p}\right) \phi(\hat{p} ; s) d \hat{p} d s-\mu$ where $\underline{p}_{t}(s), \bar{p}_{t}(s)$, and $p_{t}^{*}(s)$ are approximated as above. Using the fact that

$$
\mu \approx \int_{s} \int_{\hat{p} \leq \underline{p}(s)}\left(\log p^{*}(s)-\log \hat{p}\right) \phi(\hat{p} ; s) d \hat{p} d s+\int_{s} \int_{\hat{p} \geq \bar{p}(s)}\left(\log p^{*}(s)-\log \hat{p}\right) \phi(\hat{p} ; s) d \hat{p} d s
$$

we can rearrange the above expression to that for a small $\delta$, the response of prices on impact (in logs, and net of steady-state inflation) is approximated by

$$
\Delta \log P \approx \delta(f+S)
$$




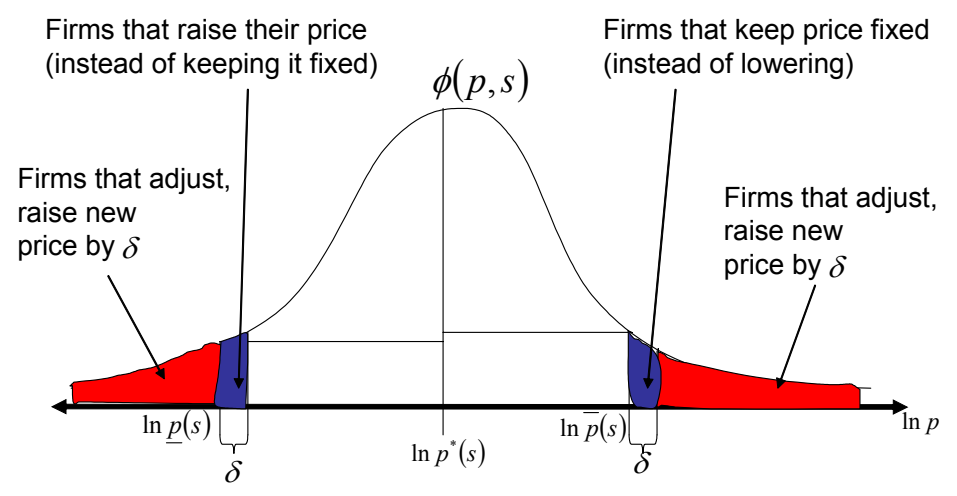

Figure 6: Intensive and Extensive Margins of Adjustment

$$
\begin{aligned}
\text { where } f & =1-\int_{s} \int_{\underline{p}(s)}^{\bar{p}(s)} \phi(\hat{p} ; s) d \hat{p} d s \\
\text { and } S & =\int_{s} \bar{K}(s) \phi(\bar{p}(s) ; s) d s-\int_{s} \underline{K}(s) \phi(\underline{p}(s) ; s) d s
\end{aligned}
$$

It then follows from the definition of $\log \hat{p}^{f}(s ; \hat{P})$ that $\delta=k \Delta \log P+(1-k) \Delta$, where $\Delta$ denotes the size of the nominal shock. Combining this with $\Delta \log P=\delta(f+S)$ implies

$$
\frac{\Delta \log P}{\Delta}=\frac{(1-k)(f+S)}{1-k(f+S)}, \text { or } \frac{\Delta \log Y}{\Delta}=1-\frac{\Delta \log P}{\Delta}=\frac{1-(f+S)}{1-k(f+S)} .
$$

$f$ is the frequency of adjustment, which measures the intensive margin: all firms that would have change their price prior to the shock raise their new price by an amount $\delta$. $S$ measures the extensive margin: some firms that prior to the shock decided to lower their price now prefer to keep it constant (first term), their density is given by the steady-state density $\phi(\bar{p}(s) ; s)$, times the magnitude of the shift in the upper Ss band, $\delta$, and these firms would have lowered their price by an amount $\bar{K}(s)$. By the same logic, the second term captures all the firms who originally chose to keep their price fixed, but now prefer to increase it. On average, they raise their price by an amount $\underline{K}(s)$. This is illustrated in Figure 6.

Figure 7 illustrates the frequency and selection effects for small $\delta$. Integrating over all $s$, the red areas in the tails measures the frequency or intensive margin, and the blue rectangles measure the selection effect or extensive margin. The magnitude of this selection effect is inversely related to the thickness of the tails of $\phi$ : for a given frequency $f$, fatter tails imply that the density is lower at the Ss-bands $\underline{p}(s)$ and $\bar{p}(s)$, and a given magnitude of price changes can be sustained only if the Ss-bands are closer to the target price. Both contribute to reducing the size of the blue rectangles. The white area measures the residual. When $k=0$, this exactly corresponds to the real 


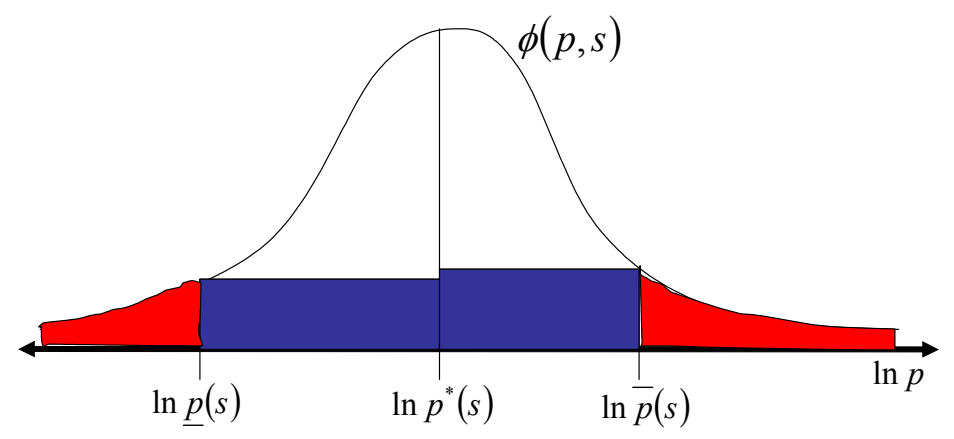

Figure 7: Frequency and Selection Effect

effect of the nominal shock on impact. When instead $k>0$, the real effect is rescaled by a factor $1 /(1-k(f+s))$, to take into account that a nominal shock of size $\Delta$ shifts the firm's Ss-bands (and hence optimal prices) only by $\delta$, which scales up the resulting output effect. ${ }^{20}$

\footnotetext{
${ }^{20}$ This graph also recovers the neutrality result of Caplin and Spulber (1987) as an extreme case. If the density $\phi(\hat{p} ; s)$ is uniform w.r.t. $\log p$, for each $s$, over an interval that strictly includes $[\underline{p}(s), \bar{p}(s)]$, the white area disappears, so that the nominal shock has no real effects. In this case, $f$ and $S$ satisfy $f=1-\int_{s^{\prime}} \hat{\phi} \int_{\log p(s)}^{\log \bar{p}(s)} d \hat{p} d s=1-$ $\int_{s}[\log \bar{p}(s)-\log \underline{p}(s)] \hat{\phi} d s$ and $S=\int_{s}[\log \bar{K}(s)-\log \underline{K}(s)] \hat{\phi} d s=\int_{s}[\log \bar{p}(s)-\log \underline{p}(s)] \hat{\phi} d s$.
} 


\begin{tabular}{|c|c|c|c|}
\hline & & \multicolumn{2}{|c|}{4 week periods $(T=4)$} \\
\hline & & $\begin{array}{l}\text { Excluding } \\
\text { markdowns }\end{array}$ & $\begin{array}{l}\text { Including } \\
\text { markdowns }\end{array}$ \\
\hline \multicolumn{4}{|c|}{ A - Frequency of price adjustment } \\
\hline 1 & Frequency & 0.26 & 0.41 \\
\hline \multicolumn{4}{|c|}{ B - Magnitude of price changes } \\
\hline 2 & Mean absolute value & 0.11 & 0.13 \\
\hline 3 & Standard deviation of non-zero changes & 0.15 & 0.19 \\
\hline 4 & Standard deviation of relative price changes & 0.07 & 0.09 \\
\hline \multicolumn{4}{|c|}{ C - Magnitude of share changes } \\
\hline 5 & Mean absolute value of log share changes & 0.17 & 0.23 \\
\hline 6 & Standard deviation of log share changes & 0.24 & 0.31 \\
\hline 7 & Standard deviation of log share changes for zero-price changes & 0.22 & 0.29 \\
\hline \multicolumn{4}{|c|}{ D - Comovement of price and share changes } \\
\hline 8 & Fraction of prices and log share changes of equal sign & 0.45 & 0.40 \\
\hline 9 & Correlation of price and log share changes & -0.08 & -0.17 \\
\hline 10 & Correlation of price and log share changes for non-zero price changes & -0.11 & -0.22 \\
\hline 11 & Correlation of relative price and log share changes & -0.23 & -0.36 \\
\hline 12 & Correlation of relative price and log share changes for non-zero price changes & -0.20 & -0.33 \\
\hline \multicolumn{4}{|c|}{ F - Price Increases vs. Decreases } \\
\hline 13 & Fraction of price increases & 0.60 & 0.54 \\
\hline 14 & Size of price increases relative to decreases & 0.86 & 0.92 \\
\hline \multicolumn{4}{|c|}{ G - High vs. Low Relative Prices } \\
\hline 15 & Frequency of high relative to low prices & 0.97 & 0.90 \\
\hline \multicolumn{4}{|c|}{ H - High vs. Low Shares } \\
\hline 16 & Frequency of high relative to low shares & 1.22 & 1.17 \\
\hline
\end{tabular}


Table 2: Prices and Market Shares, Dominiks Data, Robustness Analysis

\begin{tabular}{|c|c|c|c|c|c|c|c|c|c|c|c|}
\hline & & \multicolumn{2}{|c|}{$\begin{array}{l}\text { One week periods } \\
(T=1)\end{array}$} & \multicolumn{2}{|c|}{$\begin{array}{c}\text { One store } \\
\text { (least missing obs.) }\end{array}$} & \multicolumn{2}{|c|}{ Minimum share $=1 \%$} & \multicolumn{2}{|c|}{ Weighted averages } & \multicolumn{2}{|c|}{$\begin{array}{l}\text { Compute stats across } \\
\text { stores }\end{array}$} \\
\hline & & $\begin{array}{l}\text { Excl. } \\
\text { mkdowns }\end{array}$ & $\begin{array}{l}\text { Incl. } \\
\text { mkdowns }\end{array}$ & $\begin{array}{l}\text { Excl. } \\
\text { mkdowns }\end{array}$ & $\begin{array}{l}\text { Incl. } \\
\text { mkdowns }\end{array}$ & $\begin{array}{l}\text { Excl. } \\
\text { mkdowns }\end{array}$ & $\begin{array}{l}\text { Incl. } \\
\text { mkdowns }\end{array}$ & $\begin{array}{l}\text { Excl. } \\
\text { mkdowns }\end{array}$ & $\begin{array}{l}\text { Incl. } \\
\text { mkdowns }\end{array}$ & $\begin{array}{l}\text { Excl. } \\
\text { mkdowns }\end{array}$ & $\begin{array}{l}\text { Incl. } \\
\text { mkdowns }\end{array}$ \\
\hline \multicolumn{12}{|c|}{ A - Frequency of price adjustment } \\
\hline 1 & Frequency & 0.13 & 0.24 & 0.18 & 0.38 & 0.28 & 0.43 & 0.24 & 0.41 & 0.16 & 0.43 \\
\hline \multicolumn{12}{|c|}{ B - Magnitude of price changes } \\
\hline 2 & Mean absolute value & 0.12 & 0.15 & 0.08 & 0.12 & 0.11 & 0.14 & 0.11 & 0.13 & 0.09 & 0.14 \\
\hline 3 & Standard deviation of non-zero changes & 0.16 & 0.21 & 0.10 & 0.17 & 0.16 & 0.20 & 0.15 & 0.19 & 0.12 & 0.18 \\
\hline 4 & Standard deviation of relative price changes & 0.10 & 0.12 & 0.07 & 0.08 & 0.07 & 0.09 & 0.10 & 0.13 & 0.09 & 0.10 \\
\hline \multicolumn{12}{|c|}{ C - Magnitude of share changes } \\
\hline 5 & Mean absolute value of log share changes & 0.23 & 0.26 & 0.33 & 0.35 & 0.16 & 0.23 & 0.39 & 0.28 & 0.35 & 0.39 \\
\hline 6 & Standard deviation of log share changes & 0.35 & 0.38 & 0.43 & 0.45 & 0.23 & 0.30 & 0.53 & 0.39 & 0.46 & 0.50 \\
\hline 7 & $\begin{array}{l}\text { Standard deviation of log share changes } \\
\text { for zero-price changes }\end{array}$ & 0.28 & 0.27 & 0.41 & 0.44 & 0.21 & 0.27 & 0.49 & 0.36 & 0.45 & 0.49 \\
\hline \multicolumn{12}{|c|}{ D - Comovement of price and share changes } \\
\hline 8 & Fraction of prices and log share changes of equal sign & 0.42 & 0.27 & 0.47 & 0.41 & 0.44 & 0.39 & 0.59 & 0.39 & 0.47 & 0.42 \\
\hline 9 & Correlation of price and log share changes & -0.13 & -0.35 & -0.05 & -0.14 & -0.12 & -0.18 & 0.11 & -0.17 & -0.04 & -0.15 \\
\hline 10 & $\begin{array}{l}\text { Correlation of price and log share changes } \\
\text { for non-zero price changes }\end{array}$ & -0.21 & -0.44 & -0.10 & -0.21 & -0.17 & -0.23 & 0.18 & -0.24 & -0.10 & -0.20 \\
\hline 11 & Correlation of relative price and log share changes & -0.25 & -0.45 & -0.12 & -0.27 & -0.25 & -0.37 & -0.03 & -0.40 & -0.10 & -0.25 \\
\hline 12 & $\begin{array}{l}\text { Correlation of relative price and log share changes } \\
\text { for non-zero price changes }\end{array}$ & -0.29 & -0.47 & -0.13 & -0.28 & -0.23 & -0.36 & 0.04 & -0.39 & -0.13 & -0.25 \\
\hline \multicolumn{12}{|c|}{ F - Price Increases vs. Decreases } \\
\hline 13 & Fraction of price increases & 0.55 & 0.53 & 0.62 & 0.53 & 0.59 & 0.54 & 0.61 & 0.55 & 0.65 & 0.54 \\
\hline 14 & Size of price increases relative to decreases & 0.88 & 0.94 & 0.84 & 0.92 & 0.86 & 0.95 & 0.85 & 0.92 & 0.80 & 0.92 \\
\hline \multicolumn{12}{|c|}{ G - High vs. Low Relative Prices } \\
\hline 15 & Frequency of high relative to low prices & 0.86 & 0.95 & 0.87 & 0.86 & 0.99 & 0.93 & 0.98 & 0.88 & 0.93 & 0.92 \\
\hline \multicolumn{12}{|c|}{ H - High vs. Low Shares } \\
\hline 16 & Frequency of high relative to low shares & 1.36 & 1.54 & 1.18 & 1.14 & 1.21 & 1.13 & 0.81 & 1.18 & 1.13 & 1.15 \\
\hline
\end{tabular}


Table 3: Baseline model, Steady State, Cost and Demand shocks only

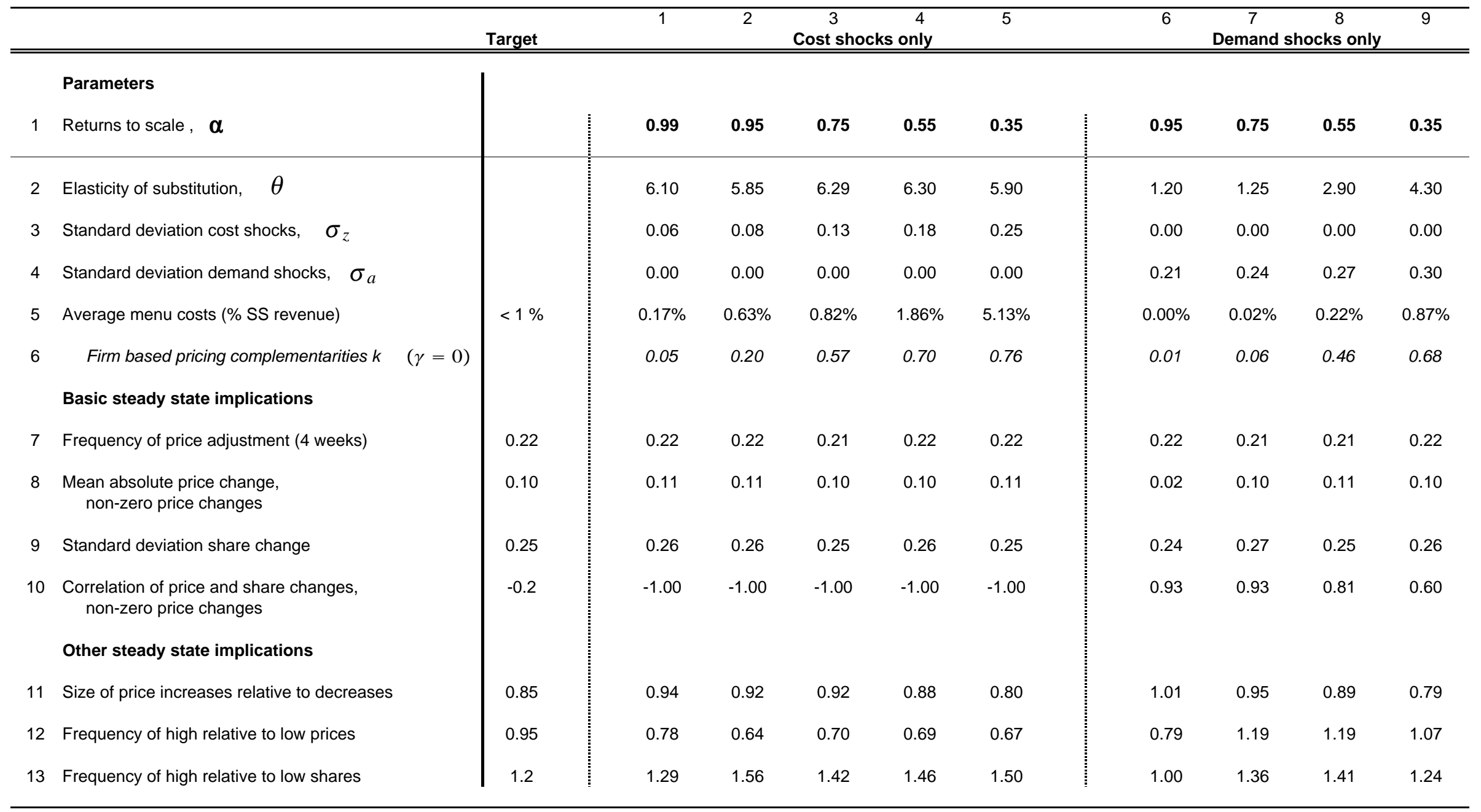


Table 4: Baseline model, Steady State, Cost and Demand shocks combined

\begin{tabular}{|c|c|c|c|c|c|c|c|c|c|}
\hline & & \multirow[b]{2}{*}{ Target } & 1 & 2 & 3 & 4 & 5 & 6 & \multirow[t]{2}{*}{7} \\
\hline & & & \multicolumn{6}{|c|}{ Cost and demand shocks combined } & \\
\hline \multirow[b]{2}{*}{1} & Parameters & & & & & & & & \\
\hline & Returns to scale, $\boldsymbol{\alpha}$ & & 0.99 & 0.95 & 0.75 & 0.65 & 0.55 & 0.35 & 0.25 \\
\hline 2 & Elasticity of substitution, $\theta$ & & 1.55 & 2.18 & 3.83 & 4.20 & 4.40 & 4.59 & 4.64 \\
\hline 3 & Standard deviation cost shocks, $\sigma_{Z}$ & & 0.06 & 0.06 & 0.08 & 0.09 & 0.10 & 0.11 & 0.11 \\
\hline 4 & Standard deviation demand shocks, $\sigma_{a}$ & & 0.21 & 0.23 & 0.25 & 0.25 & 0.26 & 0.26 & 0.25 \\
\hline 5 & Average menu costs (\% SS revenue) & $<1 \%$ & $0.05 \%$ & $0.11 \%$ & $0.54 \%$ & $0.84 \%$ & $1.31 \%$ & $2.72 \%$ & $3.84 \%$ \\
\hline \multirow[t]{2}{*}{6} & Firm based pricing complementarities $k \quad(\gamma=0)$ & & 0.01 & 0.06 & 0.41 & 0.53 & 0.60 & 0.70 & 0.73 \\
\hline & Basic steady state implications & & & & & & & & \\
\hline 7 & Frequency of price adjustment (4 weeks) & 0.22 & 0.22 & 0.22 & 0.22 & 0.22 & 0.22 & 0.22 & 0.22 \\
\hline 8 & $\begin{array}{l}\text { Mean absolute price change, } \\
\text { non-zero price changes }\end{array}$ & 0.10 & 0.10 & 0.10 & 0.10 & 0.10 & 0.10 & 0.10 & 0.10 \\
\hline 9 & Standard deviation share change & 0.25 & 0.24 & 0.26 & 0.26 & 0.25 & 0.25 & 0.24 & 0.23 \\
\hline 10 & $\begin{array}{l}\text { Correlation of price and share changes, } \\
\text { non-zero price changes }\end{array}$ & -0.20 & -0.20 & -0.19 & -0.22 & -0.21 & -0.20 & -0.20 & -0.21 \\
\hline & Other steady state implications & & & & & & & & \\
\hline 11 & Size of price increases relative to decreases & 0.85 & 0.99 & 0.98 & 0.91 & 0.89 & 0.86 & 0.80 & 0.75 \\
\hline 12 & Frequency of high relative to low prices & 0.95 & 0.87 & 0.93 & 0.92 & 0.93 & 0.93 & 0.95 & 0.96 \\
\hline 13 & Frequency of high relative to low shares & 1.20 & 1.18 & 1.19 & 1.21 & 1.21 & 1.22 & 1.25 & 1.27 \\
\hline
\end{tabular}


Table 7: Sensitivity Analysis to Model Parameters

\begin{tabular}{|c|c|c|c|c|c|c|c|c|c|}
\hline \multirow[b]{2}{*}{1} & \multirow{2}{*}{$\begin{array}{l}\text { Parameters and steady state implications } \\
\text { Returns to scale, } \alpha\end{array}$} & \multicolumn{4}{|c|}{ Duration $=2$ months } & \multicolumn{4}{|c|}{ Duration $=8$ months } \\
\hline & & 0.95 & 0.75 & 0.55 & 0.35 & 0.95 & 0.75 & 0.55 & 0.35 \\
\hline 2 & & 0.05 & 0.38 & 0.64 & 0.73 & 0.05 & 0.40 & 0.61 & 0.71 \\
\hline 3 & Average menu costs ( $\%$ SS revenue) & $0.08 \%$ & $0.38 \%$ & $1.27 \%$ & $3.16 \%$ & $0.10 \%$ & $0.42 \%$ & $1.04 \%$ & $2.53 \%$ \\
\hline 4 & Size of price increases relative to decreases & 0.99 & 0.96 & 0.92 & 0.88 & 1.00 & 0.92 & 0.89 & 0.81 \\
\hline \multirow[t]{2}{*}{5} & Frequency of high relative to low prices & 0.95 & 0.95 & 0.95 & 0.95 & 0.96 & 0.96 & 0.98 & 0.95 \\
\hline & Parameters and steady state implications & \multicolumn{4}{|c|}{ Correlation of price, share changes $=0$} & \multicolumn{4}{|c|}{ Correl. of price, share changes $=-0.4$} \\
\hline 6 & Returns to scale, $\boldsymbol{\alpha}$ & 0.95 & 0.75 & 0.55 & 0.35 & 0.95 & 0.75 & 0.55 & 0.35 \\
\hline 7 & Firm based pricing complementarities $\mathrm{k} \quad(\gamma=0)$ & 0.04 & 0.40 & 0.60 & 0.70 & 0.07 & 0.42 & 0.64 & 0.72 \\
\hline 8 & Average menu costs (\% SS revenue) & $0.06 \%$ & $0.46 \%$ & $1.21 \%$ & $2.69 \%$ & $0.14 \%$ & $0.52 \%$ & $1.49 \%$ & $3.27 \%$ \\
\hline 9 & Size of price increases relative to decreases & 0.99 & 0.91 & 0.86 & 0.80 & 0.97 & 0.92 & 0.86 & 0.79 \\
\hline \multirow[t]{2}{*}{10} & Frequency of high relative to low prices & 0.97 & 0.96 & 0.95 & 0.99 & 0.90 & 0.90 & 0.91 & 0.91 \\
\hline & Parameters and steady state implications & \multicolumn{4}{|c|}{ Mean absolute price change $=0.05$} & \multicolumn{4}{|c|}{ Mean absolute price change $=0.15$} \\
\hline 11 & Returns to scale, $\boldsymbol{\alpha}$ & 0.95 & 0.75 & 0.55 & 0.35 & 0.95 & 0.75 & 0.55 & 0.35 \\
\hline 12 & Firm based pricing complementarities $\mathrm{k} \quad(\gamma=0)$ & 0.15 & 0.69 & 0.78 & 0.85 & 0.03 & 0.27 & 0.47 & 0.62 \\
\hline 13 & Average menu costs (\% SS revenue) & $0.08 \%$ & $0.52 \%$ & $1.36 \%$ & $3.49 \%$ & $0.12 \%$ & $0.50 \%$ & $1.28 \%$ & $3.12 \%$ \\
\hline 14 & Size of price increases relative to decreases & 0.95 & 0.85 & 0.82 & 0.74 & 0.97 & 0.92 & 0.87 & 0.79 \\
\hline 15 & Frequency of high relative to low prices & 0.72 & 0.68 & 0.73 & 0.71 & 0.92 & 0.92 & 0.94 & 0.96 \\
\hline & Parameters and steady state implications & \multicolumn{4}{|c|}{ Standard deviation share change $=0.4$} & & & & \\
\hline 16 & Returns to scale, $\boldsymbol{\alpha}$ & 0.99 & 0.75 & 0.55 & 0.35 & & & & \\
\hline 17 & Firm based pricing complementarities $\mathrm{k} \quad(\gamma=0)$ & 0.01 & 0.56 & 0.74 & 0.81 & & & & \\
\hline 18 & Average menu costs (\% SS revenue) & $0.08 \%$ & $1.22 \%$ & $3.27 \%$ & $6.68 \%$ & & & & \\
\hline 19 & Size of price increases relative to decreases & 0.99 & 0.85 & 0.78 & 0.70 & & & & \\
\hline 20 & Frequency of high relative to low prices & 0.90 & 0.93 & 0.96 & 0.98 & & & & \\
\hline
\end{tabular}


Table 8: Sensitivity Analysis to Model Parameters (Autocorrelation of Idiosyncratic Shocks)

\begin{tabular}{|c|c|c|c|c|c|c|c|c|c|}
\hline & Parameters and steady state implications & \multicolumn{4}{|c|}{$\rho_{a}=0, \rho_{z}=0.5$} & \multicolumn{4}{|c|}{$\rho_{a}=0.5, \rho_{z}=0$} \\
\hline 1 & Returns to scale, $\boldsymbol{\alpha}$ & 0.95 & 0.75 & 0.55 & 0.35 & 0.95 & 0.75 & 0.55 & 0.35 \\
\hline 2 & Firm based pricing complementarities $\mathrm{k} \quad(\gamma=0)$ & 0.05 & 0.36 & 0.59 & 0.67 & 0.06 & 0.39 & 0.61 & 0.72 \\
\hline 3 & Average menu costs (\% SS revenue) & $0.10 \%$ & $0.38 \%$ & $1.02 \%$ & $2.20 \%$ & $0.09 \%$ & $0.41 \%$ & $1.22 \%$ & $2.84 \%$ \\
\hline 4 & Size of price increases relative to decreases & 0.98 & 0.93 & 0.87 & 0.81 & 0.97 & 0.90 & 0.85 & 0.79 \\
\hline 5 & Frequency of high relative to low prices & 0.87 & 0.87 & 0.87 & 0.86 & 0.99 & 1.00 & 0.99 & 1.02 \\
\hline & Parameters and steady state implications & \multicolumn{4}{|c|}{$\rho_{a}=0.8, \rho_{z}=0.5$} & \multicolumn{4}{|c|}{$\rho_{a}=0.5, \rho_{z}=0.8$} \\
\hline 6 & Returns to scale, $\boldsymbol{\alpha}$ & 0.95 & 0.75 & 0.55 & 0.35 & 0.95 & 0.75 & 0.55 & 0.35 \\
\hline 7 & Firm based pricing complementarities $\mathrm{k} \quad(\gamma=0)$ & 0.05 & 0.39 & 0.59 & 0.72 & 0.06 & 0.44 & 0.63 & 0.74 \\
\hline 8 & Average menu costs (\% SS revenue) & $0.10 \%$ & $0.51 \%$ & $1.34 \%$ & $3.04 \%$ & $0.11 \%$ & $0.62 \%$ & $1.55 \%$ & $3.87 \%$ \\
\hline 9 & Size of price increases relative to decreases & 0.98 & 0.92 & 0.87 & 0.79 & 0.98 & 0.90 & 0.85 & 0.77 \\
\hline 10 & Frequency of high relative to low prices & 0.88 & 0.84 & 0.83 & 0.85 & 1.03 & 1.07 & 1.09 & 1.08 \\
\hline
\end{tabular}


Table 9: Extensions; The Role of Quantity Data, and Matching Additional Pricing Facts

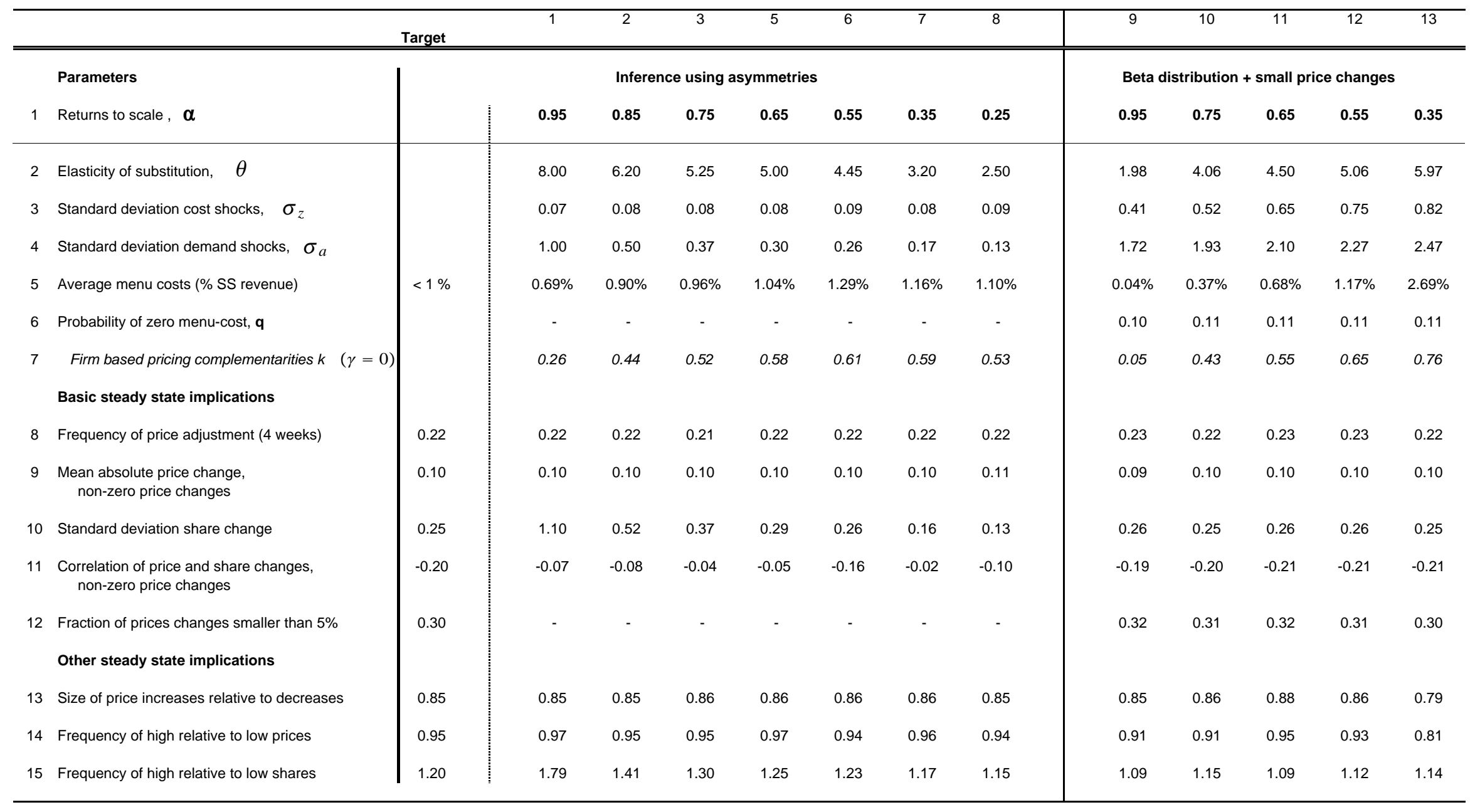

